\title{
Effects of estuarine and fluvial processes on sediment transport over deltaic tidal flats
}

\author{
David K. Ralston*, W. Rockwell Geyer, Peter A. Traykovski, and Nicholas J. Nidzieko
}

Woods Hole Oceanographic Institution

submitted May 24, 2011

revised October 7, 2011

revised January 25, 2012

* corresponding author:

Applied Ocean Physics and Engineering, MS \#11

Woods Hole, MA 02543

tel: 508-289-2587

fax: 508-457-2194

dralston@whoi.edu

Keywords: tidal flats, sediment transport, sediment trapping, distributary channels, stratification, salinity fronts, tidal asymmetry, velocity skewness, numerical model 


\section{ABSTRACT}

Tidal flats at a river mouth feature estuarine and fluvial processes that distinguish them from tidal flats without river discharge. We combine field observations and a numerical model to investigate hydrodynamics and sediment transport on deltaic tidal flats at the mouth of the Skagit River, in Puget Sound, WA during the spring freshet. River discharge over tidal flats supplies a mean volume flux, freshwater buoyancy, and suspended sediment. Despite the shallow water depths, strong horizontal density fronts and stratification develop, resulting in a baroclinic pressure gradient and tidal variability in stratification that favor flood-directed bottom stresses. In addition to these estuarine processes, the river discharge during periods of low tide drains through a network of distributary channels on the exposed tidal flats, with strongly ebb-directed stresses. The net sediment transport depends on the balance between estuarine and fluvial processes, and is modulated on a spring-neap time scale by the tides of Puget Sound. We find that the baroclinic pressure gradient and periodic stratification enhance trapping of sediment delivered by the river on the tidal flats, particularly during neap tides, and that sediment trapping also depends on settling and scour lags, particularly for finer particles. The primary means of moving sediment off of the tidal flats are the high velocities and stresses in the distributary channels during late stages of ebbs and around low tides, with sediment export predominantly occurring during spring low tides that expose a greater portion of the flats. The 3-d finite volume numerical model was evaluated against observations and had good skill overall, particularly for velocity and salinity. The model performed poorly at simulating the shallow flows around low tides as the flats drained and river discharge was confined to distributary channels, due in part to limitations in grid resolution, seabed sediment and bathymetric data, and the wetting-and-drying scheme. Consequently, the model predicted greater sediment retention on the flats than was observed. 


\section{Introduction}

Sediment transport over intertidal flats depends on a range of forcing processes, including a tidally varying water surface elevation, wind stress, and waves. On tidal flats near a river mouth, additional factors include the volume flux of river discharge and buoyancy effects associated with the fresh water. While observations and theory have evaluated the hydrodynamic and sediment-transport processes over intertidal flats dominated by tidal, wind, and wave forcing, less is known about how river input alters these unsteady, shallow flows (Le Hir et al., 2000).

Tidal forcing drives the periodic inundation and exposure that is characteristic of tidal flats. Tidal bottom stresses over flats with a uniform slope and width can be estimated to first order by assuming continuity and a rigid lid, with the result that stresses on the lower tidal flats are spatially uniform and decrease with distance above the mid-tide elevation (Friedrichs and Aubrey, 1996). The spatial gradient in velocity, in combination with settling and scour lags that tend to move sediment toward regions of lower stress (Postma, 1961), results in generally onshore sediment transport due to tidal forcing alone. To reach equilibrium, the upper flats accrete to a convex profile, decreasing the bottom slope and increasing tidal velocities (Friedrichs and Aubrey, 1996; Pritchard and Hogg, 2003). This idealization of tidal forcing does not account for flood-ebb asymmetries in velocity due to the incident tide, barotropic nonlinearities in shallow water, or bathymetric complexity (Speer and Aubrey, 1985; Friedrichs and Aubrey, 1988).

The addition of river discharge to the intertidal zone creates a shallow estuary where both baroclinic and barotropic pressure gradients alter the bottom stress and sediment flux. Strong horizontal density fronts form at the offshore edge of the tidal flats around low tide, and tidal straining of leads to strong stratification during ebbs (Ralston and Stacey, 2005). This stratification reduces bed stresses compared with unstratified flow, leading to flood dominance. Similarly, the baroclinic pressure gradient enhances flood-directed near bed velocities and stresses. The baroclinic and stratification effects on trapping sediment are well documented in deeper estuaries (Meade, 1969; Geyer, 1993), and field and numerical 
studies suggest that the flood-directed stress asymmetry due to estuarine processes can enhance trapping on tidal flats (Ralston and Stacey, 2007; Chen et al., 2010).

An important distinction from deeper estuaries is that when deltaic tidal flats are subaerial around low tide, the river continues to flow across the intertidal zone in shallow channels. Observations and modeling have suggested that offshore sediment flux can occur in these distributary channels, particularly during periods of high river discharge (Ralston and Stacey, 2007; Chen et al., 2010). While sediment export has been noted in tidal drainage channels without river input (Dyer et al., 2000; Mariotti and Fagherazzi, 2011), drainage channels are ephemeral while fluvial channels convey river discharge for the duration of the period that the flats are exposed. The river also provides a source of sediment to the intertidal zone, with sediment load in a river increasing nonlinearly with discharge (Nash, 1994).

The goal of this study is to assess how estuarine and fluvial processes affect flow and sediment transport on deltaic tidal flats. The study examines tidal flats at the mouth of the Skagit River in Puget Sound, Washington, USA during the spring freshet, when fluvial and tidal processes are dominant and wind forcing is light. The study examines how the stratification, baroclinic pressure gradient, and barotropic flux in distributary channels alter sediment fluxes in the intertidal zone. The analysis combines field observations and numerical modeling, beginning with an assessment of the ability of the model to reproduce the observed conditions.

\section{Methods}

The study area is at the mouth of the Skagit River, the largest river flowing into Puget Sound, with a mean annual discharge of $470 \mathrm{~m}^{3} \mathrm{~s}^{-1}$ (USGS \#1220050 at Mount Vernon, WA). Seasonally, the maximum discharge occurs in the late spring and early summer due to snowmelt (May-June) and in the fall and winter due to storms (November-January). The Skagit splits into two major distributaries near its mouth, the North Fork and South Fork. The river enters Skagit Bay, where a broad shallow delta forms tidal flats with across-shore width ranging from about $3 \mathrm{~km}$ off the North Fork to about $6 \mathrm{~km}$ off the South Fork. 
The tidal flats are composed predominantly of sand, with increased concentrations of mud near distributary channels and at the seaward edge (Webster et al., this issue). The tidal range varies between 2.5 and $5 \mathrm{~m}$, with mixed semi-diurnal and diurnal forcing and significant diurnal inequalities.

\subsection{Observations}

During June 2009, we conducted a field campaign with fixed and shipboard observations to measure flow and sediment transport on the Skagit tidal flats (Fig. 1). Instrument frames for high resolution sampling within about $1 \mathrm{~m}$ of the bed were deployed at five locations in the intertidal zone. Near-bed instruments included pulse-coherent acoustic Doppler profilers (pcADPs), acoustic backscatter sensors (ABSs), acoustic Doppler velocimeters (ADVs), conductivity-temperature (CT) sensors, and optical backscatter sensors (OBSs), as well as upward-looking acoustic Doppler current profilers (ADCPs) and pressure sensors. Surface buoys at each station had CTs and OBSs for near-surface water properties, and two of the buoys had meteorological instrument packages for wind, air temperature, and barometric pressure.

The instruments were deployed offshore of the South Fork in an area of sandy tidal flats with a braided network of distributary channels. Typically, the distributary channels were 0.2 to $1.0 \mathrm{~m}$ deeper than the surrounding tidal flats and were 50 to $200 \mathrm{~m}$ in width (Fig. 2). The frames were deployed in an array designed to measure gradients both across-shore (i.e., from the river mouth to Whidbey Channel, the passage east of Whidbey Island) and between the distributary channels and adjacent flats. Instruments were deployed at 3 locations along a distributary channel of the South Fork, approximately 1 km, 2 km, and $3 \mathrm{~km}$ from the seaward edge of the flats (stations 1c, 2c, and 3c). Additional frames were located parallel to 2c and 3c, but out of the channel on the adjacent tidal flats (stations $2 \mathrm{f}$ and $3 \mathrm{f}$ ).

Shipboard surveys were conducted at instrument deployment (June 1-5) and recovery (June 22-26). Tidal cycle surveys were oriented both across the tidal flats, from Whidbey Channel to the South Fork, and along-isobaths near the instrument frames. Measurements included CTD profiles of salinity, temperature, and optical backscatter, velocity profiles from an ADCP, and bathymetric measurements from an echo- 
sounder. Near-bottom and near-surface water bottle samples were obtained to calibrate the optical and acoustic backscatter sensors, including samples collected at the instrument frames. Water samples were filtered, dried, and weighed to determine suspended-sediment concentrations (SSC), which were correlated with shipboard and moored acoustic and optical backscatter.

\subsection{Numerical model}

For the hydrodynamic model, we applied the Finite Volume Coastal Ocean Model (FVCOM), (Chen et al., 2003). The grid was unstructured, with high resolution in Skagit Bay ( 15-20 m minimum spacing) and increasing in cell size toward the open boundaries ( 500 m) (Fig. 2). Significant effort went into acquiring and incorporating high-quality bathymetry data. The initial grid was based on data from a Puget Sound digital elevation model (Finlayson, 2005) and LiDAR collected by the Skagit River System Cooperative (Yang and Khangaonkar, 2009). To refine the bathymetry in the study region, we conducted small boat surveys and acquired bathymetry data from collaborators, including small-vessel surveys near the North Fork (from B. Raubenheimer and S. Elgar) and LiDAR surveys of Skagit Bay during a low tide (from J. Brozena). However, none of the survey methods adequately resolved the distributary channels from the river mouth to the seaward edge of the flats. To put these features in the grid, we used nearinfrared aerial images of Skagit Bay at low tide (from K. Hooper, Fig. 2) to determine channel locations, and assigned local channel depths (0.4- $1.0 \mathrm{~m})$ consistent with observations during the small-boat surveys.

For the Skagit simulations, we used the k- $\varepsilon$ turbulence closure scheme and low background mixing $\left(10^{-6}\right.$ $\left.\mathrm{m}^{2} \mathrm{~s}^{-1}\right)$. The model was run with 30 vertical sigma levels. Bottom roughness was set to a uniform $z_{0}$ of 1.5 mm on the tidal flats based on calibration to observed salinities and near-bed stresses, but this value is not well constrained as a $z_{0}$ of $0.5 \mathrm{~mm}$ produced higher skills at some stations. For comparison, $z_{0}=1.5 \mathrm{~mm}$ corresponds with a drag coefficient $\left(C_{d}\right)$ of 0.0038 , for a reference velocity $1 \mathrm{~m}$ above the bed.

Open boundaries were located west of Deception Pass, south of Saratoga Passage, and at the northern end of Swinomish Channel (Fig. 2). Water surface elevations at the open boundaries combined tidal 
harmonics with the observed subtidal water level at the tidal reference stations of Seattle (\#9447130) and Port Townsend, WA (\#9444900). In addition, a pressure gradient between the southern and western boundary was incorporated based on a larger scale model of Puget Sound and the Salish Sea (Sutherland et al., 2011). Simulations from the regional model were not available for the period of study, so the pressure gradient was based on results from simulations of 2005 and 2006, yielding an average difference in water surface elevation of $4.3 \mathrm{~cm}$ between the southern and western boundaries. Skagit River discharge was from the station at Mount Vernon (\#12200500) (Fig. 3). Salinities at the offshore boundaries were based on climatology constructed from surveys from the Washington Department of Ecology Marine Water Monitoring program (http://www.ecy.wa.gov/apps/eap/marinewq/mwdataset.asp).

Comparisons between the model and observations suggested that local winds affected the mean currents and stratification. When the model was forced with spatially uniform winds from the meteorological buoys, model skills improved for salinity and velocity. However, differences in recorded winds at stations separated by just a few kilometers indicated that the wind field was highly heterogeneous due to interaction with the surrounding topography (Raubenheimer et al., this issue). To incorporate spatial and temporal variability in the wind field, we developed a regional atmospheric model using the Weather Research and Forecasting model (WRF), and used results from the WRF simulations to force FVCOM. A sediment transport module in FVCOM based on the Community Sediment Transport Model System (Warner et al., 2008) was run with 3 sediment classes, with settling velocities $\left(w_{s}\right)$ of $10 \mathrm{~mm} \mathrm{~s}^{-1}, 1 \mathrm{~mm} \mathrm{~s}^{-1}$, and $0.1 \mathrm{~mm} \mathrm{~s}^{-1}$, representative of fine sand, silt, and fine silt (Table 1). Sediment erosion parameters were based on similar size classes used in other recent estuarine and tidal-flat modeling studies (Warner et al., 2008; Chen et al., 2010). The sediment was treated as non-cohesive, with no bed consolidation. The sediment bed was initialized uniformly with a sediment class distribution based on a limited number of bed samples from the tidal flats: $40 \% 10 \mathrm{~mm} \mathrm{~s}^{-1}, 45 \% 1 \mathrm{~mm} \mathrm{~s}^{-1}$, and $15 \% 0.1 \mathrm{~mm} \mathrm{~s}^{-1}$. A more extensive survey of the bed sediments in Skagit Bay found that the middle and upper flats were dominated by sand 
( $\sim 97 \%)$ and that mud was a substantial portion of the bed ( 20-60\%) only near distributary channels and on the lower flats (Webster et al., this issue).

For suspended sediment input from the river, a rating curve was based on data from the USGS station at the Mount Vernon (E. Grossman, pers. comm.). Suspended-sediment concentration in the river scaled with discharge according to

$$
C=C_{0}\left(Q_{r} / Q_{r 0}\right)^{1.4}
$$

where $C$ is the suspended-sediment concentration $\left(\mathrm{mg} \mathrm{L}^{-1}\right), C_{0}$ is a reference concentration $\left(165 \mathrm{mg} \mathrm{L}^{-1}\right)$, $Q_{r}$ is the discharge $\left(\mathrm{m}^{3} \mathrm{~s}^{-1}\right)$, and $Q_{r 0}$ is the mean annual discharge $\left(470 \mathrm{~m}^{3} \mathrm{~s}^{-1}\right)$. This formulation was largely consistent with more recently released observations, where the best fit to measurements over a full

year found that $C \sim Q_{r}^{1.43}$ (Curran et al., this issue). Eqn. (1) was based on data from a winter storm event, but the subsequent fit to the full year of data produced a lower effective $C_{0}$ of about $110 \mathrm{mg} / \mathrm{L}$.

\subsection{Model skill}

To assess model performance, we compared time series from the simulations with observations of water level, salinity, velocity, stress, and suspended-sediment concentration (conditions are described in detail in Section 3). We focused on two performance metrics: correlation coefficient (R) and skill score (SS). The correlation coefficient reflects the covariance between the model and the observations

$$
R=\sigma_{\mathrm{m}}^{-1} \sigma_{\mathrm{o}}^{-1} \frac{1}{N} \sum_{i=1}^{N}\left(X_{\mathrm{m}, \mathrm{i}}-\overline{X_{m}}\right)\left(X_{\mathrm{o}, \mathrm{i}}-\overline{X_{o}}\right)
$$

where $X_{m}$ and $X_{o}$ are the values from the model and observations, an overbar represents a time average, $N$ is the number of observations, and $\sigma_{m}$ and $\sigma_{o}$ are standard deviations of the model and observations. The skill score is based on the mean square error between the model and the observations, normalized by the standard deviation of the observations: 


$$
S S=1-\sigma_{\mathrm{o}}^{-2} \frac{1}{N} \sum_{i=1}^{N}\left(X_{\mathrm{m}}-X_{\mathrm{o}}\right)^{2}
$$

(Murphy, 1988). The maximum skill score is 1 when the model and observations agree exactly, and a skill score of 0 indicates that the mean square error is the same magnitude as the variance of the observations. The skill score can be related to the correlation coefficient and two additional terms:

$$
S S=R^{2}-\left(R-\frac{\sigma_{\mathrm{m}}}{\sigma_{\mathrm{o}}}\right)^{2}-\left(\frac{\overline{X_{m}}-\overline{X_{o}}}{\sigma_{\mathrm{o}}}\right)^{2}
$$

(Murphy, 1988). The second term on the right represents the difference in variance between the model and the observations, and it vanishes when the slope of the regression line is equal to 1 . The last term is the mismatch between the means of the model and observations, and it corresponds with the intercept of the linear regression. The skill score has a maximum equal to $R^{2}$, but decreases due to mismatches in the amplitude of the variability or the temporal means.

Correlation coefficients and skill scores over the deployment are given in Table 2. For water surface elevations, $R^{2}$ and $S S$ were extremely high (>0.99). Velocities on the flats were also well captured by the model, with high correlations (0.88-0.95) and skill scores (0.86-0.95) for the depth-averaged eastward velocity $\left(u_{e}\right)$, which corresponds with the across-shore direction. The northward velocity component $\left(v_{n}\right)$ was reproduced with moderate skill ( $R^{2}$ of 0.39 to 0.62 and $S S$ of 0.33 to 0.56 ). The northward or alongshore velocities were weaker than the across-shore velocities, and were more sensitive to poorly constrained forcing factors like the wind field and the large-scale pressure gradient.

Salinity variations at tidal and spring-neap time scales corresponded well with the observations. In particular, correlations and skill scores for near-bottom salinity were high ( $R^{2}$ of 0.61 to 0.81 and $S S$ of 0.42 to 0.72 ). Bottom salinity skills decreased with distance onshore, as small variations in the position of the tidal salinity front led to large differences in salinity on the upper flats. Correlations and skill scores were lower for surface salinity than for bottom salinity. While the across-shore position of the bottom 
salinity front depended largely on $u_{e}$ (which was well represented by the model), the surface salinity fronts had complex lateral structure and were more sensitive to winds and along-shore currents (Mullarney and Henderson, 2011). While surface salinity fronts in the model were similar in magnitude to the observations, differences in the phasing at the observation points produced large skill errors.

Accurately reproducing bottom stress is an important component of modeling suspended sediment because of the dependence of resuspension on excess stress. In the Skagit model, the bottom stresses had reasonable correlations with the observations ( $R^{2}$ of 0.31 to 0.63$)$, but skill scores were lower. Observed stresses were calculated from the ADV measurements in 10-minute bursts using the inertial dissipation method. The model used a spatially uniform $z_{0}$ of $1.5 \mathrm{~mm}$ on the flats, which produced bottom stresses that agreed well with some of the observations ( $S S=0.45$ at station 3c) but produced higher stresses than observed at other stations ( $S S=-4.4$ at $1 \mathrm{c}$ ). The discrepancy suggests spatial, and potentially temporal, variability in $z_{0}$ due to bedforms and bed composition (Whitehouse et al., 2000). If model stresses were adjusted to a local $C_{d}$ more consistent with the observations (thereby changing the slope of the regression line), skill scores improved significantly ( $S S=0.55$ at $1 \mathrm{c})$. Such a local optimization of $C_{d}$ to match observed stresses would imply changes in $C_{d}$ by factors between 0.5 and 1.3. Adding spatial and temporal variability to $z_{0}$ might produce higher skills for bottom stress (and suspended sediment). However, with observations at only 5 locations and no identifiable trends in the model-data mismatch, we could not define a map of optimal $z_{0}$. In addition to $C_{d}$, the model under-predicted the velocities of channelized flow around low tide (discussed in detail later), which contributed significantly to the bed-stress error.

While temporal and spatial patterns of suspended sediment in the time series and spatial surveys from the observations had strong similarities to the model results, correlations ( $R^{2}$ of 0.13 to 0.40$)$ and skill scores (SS of -5.8 to 0.39 ) for suspended sediment were lower than for the other variables. Sediment skills were highest at stations where the bottom stress best matched observations, indicating that local resuspension was a significant part of the suspended sediment signal. The model was compared against sediment concentrations from acoustic measurements by ADVs and ABSs, as OBS data were significantly noisier. 
At locations where both acoustic instruments were deployed, the correlations ( $R^{2}$ of 0.43 to 0.88 ) and skill scores (SS of 0.14 to 0.44 ) between the instruments were moderate, providing an indication of the level of uncertainty in the suspended-sediment observations.

In model development, several modifications were made to increase model skill. Modifications to the grid based on bathymetry data collected on the flats and in the river led to significant improvements in skill, particularly in the across-shore position of the salinity front and in the distribution of discharge between the North and South Forks. The salinity skill also improved with an increase in the number of vertical layers from 20 to 30, a surprising result given the shallow depths of the tidal flats. Increased vertical resolution helped reduce numerical mixing in Whidbey Channel and Saratoga Passage, where the halocline intersects steeply sloping bathymetry. With 20 layers, water advecting onto the flats during flood tides was too fresh due to the numerical mixing offshore; increasing to 40 layers did not produce additional increases in salinity skill.

\section{Observations and model results}

In this section, we describe conditions on the Skagit tidal flats during June 2009, including the tidal and river forcing, salinity and stratification, velocities and bed stress, and suspended-sediment concentrations. The findings presented incorporate both observations and model results.

\subsection{Tides, river discharge, and winds}

The observation period corresponded with the spring freshet, with a maximum discharge of $930 \mathrm{~m}^{3} \mathrm{~s}^{-1}$ in early June (Fig. 3). Discharge decreased through the observations to about $450 \mathrm{~m}^{3} \mathrm{~s}^{-1}$ by the end of the month. The observations spanned two spring tides and an intervening neap, with larger spring tides occurring toward the end of the month. Winds during the observations were mostly light and dominated by a diurnal sea breeze, with sustained winds exceeding $7 \mathrm{~m} \mathrm{~s}^{-1}$ for only brief periods.

\subsection{Salinity}


Salinity and stratification were highly variable at tidal and spring-neap time scales. The river delivered fresh water to the upper flats, and the bottom salinity at the seaward edge was characteristic of Puget Sound water, 30 psu. Around low tide, the river flowed across exposed tidal flats in distributary channels to a bottom salinity front at the seaward edge (Fig. 4). During the rising tide, the salinity front advected across the tidal flats as a narrow, unstratified region of strong horizontal salinity gradient ( 30 psu over $<4 \mathrm{~km}$ ). In both the observations and the model, the near-surface region behind the flooding front was weakly stratified, as low salinity water from the previous ebb returned onshore. During ebbs, a surface layer of nearly fresh water accelerated offshore, straining the front into strong stratification. Stratification persisted through much of the ebb with the tide falling and high salinity bottom water moving offshore, but mixing in shallow water eliminated the stratification by the end of many ebbs.

The tidal progression of the salinity field (Fig. 4) is typical of shallow, strongly forced salt-wedge estuaries. Horizontal salinity gradients are generated and advected during flood tides, and stratification is created and then mixed away during ebbs (Ralston et al., 2010). The example shown had moderate tides and relatively high discharge (June 4-5), and the strength and timing of the stratification varied with tidal and fluvial forcing (Fig. 5). During neap tides with weaker velocities and greater water depths, strong stratification persisted on the flats over multiple tidal cycles rather than mixing each ebb. In the perigean spring tides (June 22-26), stratification occurred during the flood and early ebb but was mixed vertically early in the strong ebb. Conditions were saltier and less stratified during the perigean spring than during spring tides earlier in the month, due both to the increased tidal amplitude and decreased river discharge.

While the across-shore tidal sections are useful for describing the dominant tidal variability in salinity fronts and stratification, the bathymetry of Skagit Bay complicates this basic 2-d framework (Fig. 6). The across-shore transects (Fig. 4) were between the South Fork and the seaward edge of the flats. The North Fork provides another major source of fresh water. The distance between the river mouth and the seaward edge of the flats is less in the north due to the constraint of Whidbey Island, and the channel network is more focused, about 2-3 km wide compared with 5-6 km width in the south. Consequently, model results 
suggest that river velocities are higher in the north, strong river flow extends to the seaward edge of the flats during ebbs, and high-salinity water does not propagate as far landward during flood tides (Fig. 6).

The tidal flats between the North and South Forks do not have direct fluvial inflow at the landward edge, and thus have different salinity and stratification characteristics. The horizontal salinity gradients in this region were much weaker, and generally oriented along isobaths rather than across-shore (e.g., Fig. 6b). The across- and along-shore tidal currents were similar in magnitude in this region, and the stratification was generally weaker because of less tidal straining. Outflow from the North and South Forks advected by the tides and wind provided the dominant buoyancy inputs in this central region.

\subsection{Velocity and bed stress}

Velocities on the tidal flats varied at diurnal and fortnightly time scales (Fig. 7). During spring tides, depth averaged velocities at times exceeded $0.6 \mathrm{~m} \mathrm{~s}^{-1}$, with higher velocities observed in the channels and on the lower flats. During neaps, maximum tidal velocities were 0.1 to $0.2 \mathrm{~m} \mathrm{~s}^{-1}$. The mixed tidal forcing created substantial diurnal inequalities. For most of the observations, the diurnal cycle had a large flood tide, an extended period of high water with a small ebb and small flood, and then a large ebb toward lower low water. The tidal velocities corresponded with the asymmetry in water-surface elevation, with maximum velocities during the large flood and ebb and much weaker velocities during the extended high water (Fig. 8). In addition to the tides, the volume flux from the Skagit River imposed mean offshore velocities that averaged 0.03 to $0.05 \mathrm{~m} \mathrm{~s}^{-1}$, with greater mean velocities in the channels than on the flats.

The extreme variations in stratification resulted in variations in the vertical structure of velocity (Fig. 4). During flood tides, the water column at the salinity front was weakly stratified and weakly sheared. During ebbs, stratification increased and shear developed across the pycnocline as the surface layer accelerated offshore while near-bed velocities remained weak. Depending on the tidal amplitude and river discharge, the two-layer structure could persist through the ebb or mix away, with late ebb velocities 
returning to a more weakly sheared profile. The highest velocities, approaching $1 \mathrm{~m} \mathrm{~s}^{-1}$, occurred in the distributary channels around low tide as relatively shallow $(\sim 0.5 \mathrm{~m})$, seaward flows of the river discharge.

As with velocity, bottom stress varied with the diurnal and spring-neap forcing (Figs. 7 and 8). During the larger spring tides late in the month, bottom stresses exceeded $1 \mathrm{~Pa}$ in the channel and were slightly less on the flats. During the neap tides, maximum tidal stresses were 0.1 to $0.2 \mathrm{~Pa}$, below the noise limit for the observations. Maximum stresses corresponded with the larger flood and ebb tides each diurnal period, with negligible bottom stresses during the smaller ebb and flood around high water. Stress asymmetries varied with tidal forcing and position across the flats, as peak ebb stresses occurred after the tide had receded and the river continued to flow in the channels. The periods of channelized flow with high velocities and bed stresses were not particularly well represented in the model, with channel velocities and stresses in the model that were significantly less than observed (e.g., Fig. 8, station 2c).

\subsection{Suspended sediment}

Suspended-sediment concentrations observed on the tidal flats followed a spring-neap pattern like that of bed stress. During the early spring tides, maximum near-bottom concentrations were around $200 \mathrm{mg} \mathrm{L}^{-1}$ based on the acoustic measurements. Sediment concentrations had tidal maximums $<50 \mathrm{mg} \mathrm{L}^{-1}$ during the neap, when stratification persisted over multiple tidal cycles and bed stresses were weak. The maximum sediment concentrations occurred during the perigean spring tides (Fig. 9). During the large flood and ebb with inundation and drying of the tidal flats, maximum near-bottom concentrations were 200 to $500 \mathrm{mg} \mathrm{L}$

${ }^{1}$, generally with higher concentrations during the ebb approaching lower low water. The intervening weaker ebb and flood around high water had sediment concentrations that decreased to $<50 \mathrm{mg} \mathrm{L}^{-1}$.

Across-shore sections from the model along a channel during spring tides detail the suspended sediment, stress, and stratification distributions through a diurnal tidal cycle (Fig. 10). During the large flood tide, a salinity front propagated up the flats and the water column was unstratified (Fig. 10a). Bed stresses and suspended-sediment concentrations were elevated behind the front at the seaward edge of the flats. In the 
channel above the tide level, the river discharged as a shallow flow with high bed stresses ( $>1 \mathrm{~Pa})$ and suspended-sediment concentrations $\left(>400 \mathrm{mg} \mathrm{L}^{-1}\right)$. Later in the large flood, the tide has inundated the flats and drowned the distributary channel network (Fig. 10b). The maximum suspended-sediment concentrations advected with the salinity gradient and were located on the mid-flat.

During the smaller ebb and flood around high water, sediment concentrations remained low. Stratification was strong and velocities were weak at the end of the smaller ebb, and stresses and suspended-sediment concentrations were negligible (Fig. 10c). During the stronger ebb, greater velocities with shallower water depths mixed the stratification, increasing bed stresses, and resuspending sediment. Around mid-tide, different segments of the across-shore profile reflected the balance between stress and stratification (Fig. 10d). Stresses were high and sediment resuspension had begun by mid-tide on the lower flat (0-2 km from the seaward edge) because this region contained unstratified, high-salinity Puget Sound water at the start of the large ebb. Mid-flat (2-4 km), stratification remained strong, bottom stresses were weak, and sediment concentrations were low. The stratification on the mid-flat was beginning to mix due to increasing bottom stress and shear, seen in the thickening of the pycnocline (relative to Fig. 10c). On the upper flat (4-6 km), water depths had fallen and vertical mixing was nearly complete, and bed stresses and sediment concentrations had increased. Finally, toward the end of the large ebb, stratification had broken down over the entire flat (Fig. 10e). Bed stresses and sediment concentrations increased below the tide level, but even higher stresses and concentrations were in the exposed channel that continued to carry river discharge. For sediment transport, the period of high stress and sediment concentration at the end of the large ebb was critical to moving sediment seaward. The seaward flux occurred predominantly in the channels, as the flats outside the channels did not have this extended period with high seaward stress to counter the reduction in bottom stress by stratification earlier in the ebb.

\section{Analysis}

\subsection{Velocity scaling}


To analyze sediment fluxes over the tidal flats, we consider velocity scales for the tides and the river. In a simplified tidal flat with uniform slope $(\alpha)$ and constant width, a scale for the maximum tidal velocity can be derived by assuming a flat water surface and continuity:

$$
u_{t}=\frac{a_{0} \omega}{\alpha}
$$

where $a_{0}$ is the tidal amplitude and $\omega$ is the tidal frequency (Friedrichs and Aubrey, 1996). In southern Skagit Bay, the tidal flats have a relatively uniform slope of about $6 \times 10^{-4}$, and using semi-diurnal tidal amplitudes of 1 to $2 \mathrm{~m}$, we calculate $u_{t} \approx 0.25$ to $0.5 \mathrm{~m} \mathrm{~s}^{-1}$. This is the maximum tidal velocity on the lower flats, and above the mid-tide level the velocity decreases parabolically toward 0 at the high tide.

In addition to the tidal volume flux, the river flux enhances seaward velocities. When the tide is high and the flats are inundated, the river contribution to the total velocity is small. For example, assuming a river discharge $\left(Q_{r}\right)$ between 500 to $900 \mathrm{~m}^{3} \mathrm{~s}^{-1}$ and that $45 \%$ goes to the South Fork, a water depth $(h)$ of $2 \mathrm{~m}$, and an along-shore spread of the region of river influence at high water $\left(b_{H W}\right)$ of $5 \mathrm{~km}$ (e.g., Fig. 6), the fluvial contribution to the depth-average velocity is $u_{r} \approx 0.05$ to $0.09 \mathrm{~m} \mathrm{~s}^{-1}$. However, when the tide level has fallen, the river continues to flow in the distributary channel network and velocities are substantially higher. The channelized velocities can be scaled according to open channel flow, which assumes that the water surface slope is equal to the bed slope and is balanced by friction:

$$
C_{d} u_{r}^{2}=\alpha g h
$$

where $C_{d}$ is a drag coefficient and $g$ is gravitational acceleration. The fluvial velocity scale can be related to discharge by assuming an effective width of the outflow, which in this case is the cumulative width of the distributary channels, so that

$$
u_{r}=\left(\frac{\alpha g Q_{r}}{C_{d} b_{L W}}\right)^{1 / 3}
$$


Estimating the effective channel width when the flats are exposed as $b_{L W} \approx 0.6 \mathrm{~km}$ and assuming $C_{d} \approx$ 0.004 , an elevated roughness due to channel bedforms and the shallow flow, we estimate $u_{r} \approx 0.8$ to $1.0 \mathrm{~m}$ $\mathrm{s}^{-1}$ for the observed range of $Q_{r}$. We assumed $\alpha$ equaled the overall slope of the tidal flats $\left(6 \times 10^{-4}\right)$, but channels on the lower flats were generally more incised than on the upper flats so the the channel bed slope may be greater; using a steeper channel slope would increase the fluvial velocity scaling by about $10 \%$. On the upper flats, the channels are exposed during some part of most tidal periods, but on the lower flats, the channels only are exposed during brief periods around spring low tides. For sediment transport, an important distinction between tidal and fluvial velocity scales is that $u_{t}$ is symmetric between flood and ebb (assuming a symmetric tide and neglecting non-linearities), while $u_{r}$ is only oriented offshore.

The calculated tidal and fluvial velocity scales were generally consistent with the observations. Velocities as a function of water depth are shown for the three stations in a channel, with maximum ebb-directed velocities occurring at shallow water depths and approaching the river scaling of $\sim 0.9 \mathrm{~m} \mathrm{~s}^{-1}$ (Fig. 11a). In contrast, flood velocities and ebb velocities at higher tidal stages rarely exceed the tidal scaling of $\sim 0.4 \mathrm{~m}$ $\mathrm{s}^{-1}$. The observations were on the lower flats, near the subtidal boundary. Velocities versus depth from the model along one of the distributary channels are also shown (Fig. 11b). The patterns were similar, in that the tidal scaling applied at higher stages, and that around low tide, ebb-directed velocities were enhanced. The channelization was more pronounced on the middle and upper flats where exposure by low tides was more frequent and longer duration. However, the fluvial velocities in the model, while elevated compared to the tidal velocities, were much less than the observed velocities or $u_{r}$. The model underpredicted the low-tide channel velocities, and consequently calculated bed stresses and sediment concentrations that were lower than observed. We address these limitations in greater detail in the Discussion.

The velocity asymmetry due to channelization around low tide produced an asymmetry in bed stress (Fig 11c). Maximum stresses were ebb-oriented due to the river flow, and were typically between 1 and 2 Pa. While the scaling assumed a uniform slope for the flats, local variations in across-shore slope resulted in spatial variability in bed stress, similar to the riffle and pool structure of terrestrial streams. The maximum 
stresses associated with the tidal forcing (e.g., on the lower flats with depths $>1 \mathrm{~m}$ ) were significantly weaker than the stresses during shallow channel flow. Scaling $\tau_{b}=\rho_{0} C_{d} u_{t}^{2}$, the expected tidal stress is about $0.5 \mathrm{~Pa}$, similar to the stresses during flood tides over most of the section. In contrast, stresses during ebbs were substantially weaker than this scaling when water depths were greater than about $2 \mathrm{~m}$. In the model, near-bed stresses were reduced by stratification early and mid-ebb (Figs. 4 and 10), and as water levels decreased late in the ebb, stratification mixed away and stresses increased.

The relationship between suspended-sediment concentration and tidal stage was similar to that of bed stress (Fig. 11d). The highest concentrations were directed seaward when the river discharge was confined to the channels. As with stress, sediment concentrations were greater during floods than ebbs at a given water depth, except when the depth decreased below about $2 \mathrm{~m}$. An important caveat is that these results come from a channel, and channels represent a small fraction of the total surface area of the tidal flats. Outside of the channels or in the broad region between the North and South Forks, extended periods of high stress and suspended-sediment concentration did not occur late in the ebb. The stratification asymmetries between flood and ebb occurred at scales much broader than individual channels, and flood dominance of stress and suspended-sediment flux were observed on the flats outside the channels.

\subsection{Tidal asymmetry}

To assess the net effects of the asymmetries in velocity, stress, and suspended sediment, we use the skewness in near-bottom velocity, $u_{b}$. The amplitude and sign of the velocity skewness depend on the asymmetry between peak flood and ebb velocities, and the approach is better suited to the truncated tides of the intertidal zone than traditional harmonic analysis (Nidzieko and Ralston, in press). We are interested in the effects of velocity skewness on sediment transport, and sediment-transport scales roughly as $u_{b}{ }^{3}$, with sediment flux $=u_{b} S S C \sim u_{b} \tau_{b} \sim u_{b}{ }^{3}$. To include effects of mean currents on the net sediment flux, we calculate the skewness by taking moments about 0 rather than the temporal mean. Specifically, skewness is defined as the third moment normalized by the second moment to the $3 / 2$ power: 


$$
\begin{aligned}
& \gamma_{0}=\frac{\mu_{3}}{\mu_{2}^{3 / 2}} \\
& \mu_{m}=\frac{1}{N-1} \sum_{i=1}^{N} u_{i}^{m}
\end{aligned}
$$

where the $\mu_{m}$ is the $m$-th moment about zero and $N$ is the number of samples. With this definition, positive skewness is consistent with flood-dominant transport and negative skewness corresponds with ebbdirected $u_{b}{ }^{3}$. We also calculate the skewness of the rate of change in tidal elevation, $\partial \eta / \partial t$. If the velocity and water surface are in quadrature (90 degrees out of phase) and there is no mean flow, the skewness of $u_{b}$ and $\partial \eta / \partial t$ will be equal. Evaluating differences in skewness between $u_{b}$ and $\partial \eta / \partial t$, we can distinguish the tidal asymmetry due to the external forcing from asymmetries generated by local processes. To quantify variability due to shifts in tidal amplitude and river discharge, we calculate the third moment $\left(\mu_{3}\right)$ over a moving window of 40 hours, but normalize to the second moment $\left(\mu_{2}\right)$ of the entire record to retain differences in magnitude through the observation period.

A variety of processes can contribute to tidal velocity skewness (Friedrichs, 2011), and many are relevant on the Skagit tidal flats. Diurnal inequalities in the incident tide can produce skewness in $\partial \eta / \partial t$ and thus $u_{b}$. For example, when higher high water immediately precedes lower low, $\gamma_{0, \partial \eta / \partial t}$ is negative and velocities are ebb dominant. In Puget Sound, the skewness in $\partial \eta / \partial t$ varies at spring-neap and seasonal time scales, and during the observations the incident tide had periods of positive and negative skewness (Fig. 12a). The velocity skewness from the incident tide depends in part on the local barotropic response. In shallow water, finite wave speed leads to shorter, faster flood tides and longer, slower ebbs, with net flood velocity skewness that increases with $a_{0} / h$ (Speer and Aubrey, 1985). Alternatively, frictional drainage during the ebb can result in a phase lag in $\partial \eta / \partial t$ across the tidal flats, leading to ebb dominance that depends on $a_{0} / h$ and the bed slope (Friedrichs et al., 1992; Nidzieko and Ralston, in press).

In estuaries, asymmetries in the density gradient and stratification also affect velocity skewness. The density gradient enhances near-bottom velocities during flood tides and reduces near-bottom velocities 
during ebbs, for a net flood-dominant effect. Asymmetry in stratification also creates flood-dominance in near-bottom velocity and stress, as stratification and shear increase during ebbs and bottom velocities are small relative to surface currents. In contrast, channelized river discharge over exposed tidal flats provides a mechanism for ebb-dominance. These high channel high stresses are particularly important for moving larger particles, as tidal and estuarine stresses rarely exceed the critical stress for erosion of sand.

To assess the spatial and temporal variability in velocity skewness, we took time series of near-bottom velocities from the model for two transects across the intertidal zone: in a distributary channel and on the adjacent flats (Fig. 12c/d). The velocity asymmetry depends on the skewness in the incident tide (top panels) and the local barotropic and baroclinic processes. In the channel, a dominant source of variability was the enhancement of ebb-directed (negative) skewness during the spring tides due to fluvial discharge. The effect was most pronounced in the upper channel that was exposed during moderate spring-tide low waters, and the ebb-directed fluxes extended more seaward during the stronger tides late in the month. In the lower channel, the baroclinic pressure gradient and stratification enhanced flood-directed near bottom velocity and stress such that skewness was more positive than the incident tide. The model tended to underestimate ebb velocities around low-tide, so the actual enhancement of seaward skewness due to channelization may extend to the seaward edge during spring tides.

On the flats outside the distributary channel, the skewness varied with the incident tide, but was enhanced toward positive (flood) values by the baroclinic pressure gradient and stratification (Fig. 12d). The seaward barotropic contribution of the river discharge had little effect outside the channels, and the asymmetry was more uniform across the flat. The dominant driver of variability in velocity asymmetry outside the channel was the temporal modulation of the asymmetry in the incident tide (Nidzieko, 2010).

To evaluate the contributions of the various mechanisms to the net velocity asymmetry, we ran test cases using the model: a barotropic case in which density had no effect, and a tidal case without river discharge. For the barotropic case, the velocity skewness in the channel had ebb-dominant periods during spring 
tides due to the river discharge around low tide, as in the full-physics simulation (Fig. 12e/f). However, without the baroclinic pressure gradient and stratification, the lower channel and the flats outside the channel no longer had the extended periods of flood dominance. By retaining the volume flux of the river but eliminating density effects, the barotropic case produced greater ebb dominance. In the case without river input, the velocity skewness both in and out of the channel largely reflected the asymmetry of the incident tide (Fig. 12g/h). All of the cases had the same bathymetry, including the distributary channel network. Drainage of the barotropic tide into these channels enhanced ebb-dominance on the upper flats relative to outside the channel, but the drainage effect was modest compared with the river flux.

The velocity skewness is a convenient measure of the potential for sediment transport, but asymmetries in near bottom velocity are not the only mechanisms for generating tidal asymmetric sediment flux. Settling and scour lags enhance landward sediment flux due to spatial gradients in tidal energy (Straaten and Kuenen, 1958; Postma, 1961; Dronkers, 1986). The double high tides in Skagit Bay enhance settling lag by extending the period of low stress between the large flood and large ebb. Bottom stresses during the small ebb and flood were insufficient to resuspend sediment, and the high-water slack effectively extended for 6 hours or more.

In the model, both velocity asymmetry and settling and scour lags appear to be important to the net sediment flux (Fig. 13). We calculated net sediment flux over diurnal tidal cycles and compared against the calculated near-bottom velocity skewness, distinguishing among the sediment size classes $\left(w_{s}=0.1,1\right.$, and $10 \mathrm{~mm} \mathrm{~s}^{-1}$ ). In all of the size classes, net sediment flux varied approximately linearly with the local velocity skewness, and offshore fluxes had negative skewness, consistent with the assumption that sediment flux scales with $u_{b}{ }^{3}$. The variability about the linear relationships depended on settling velocity. For slowly settling particles, the net flux depended not only on velocity skewness but also the duration of high slack water, with more landward flux during diurnal periods with extended high slacks. Faster settling particles $\left(10 \mathrm{~mm} \mathrm{~s}^{-1}\right)$ did not have a strong dependence on slack duration. Considering a 1-m-deep water column, the settling time scale for the $10 \mathrm{~mm} \mathrm{~s}^{-1}$ sediment is $\sim 2$ minutes, while sediment with a 
settling velocity of $0.1 \mathrm{~mm} \mathrm{~s}^{-1}$ requires $\sim 3$ hours. For the tides during this period, slack-water duration correlated with greater diurnal tidal amplitude, enhancing the settling lag effect. This correlation would not necessarily be the case in other tidal regimes or in the Skagit at other times of the year.

\subsection{Sediment flux}

The near-bottom velocity asymmetry suggests that outside of channels, the sediment flux should be largely landward due to estuarine enhancement of the incident asymmetry. In channels, the river discharge creates an ebb-directed flux when the tide recedes to expose the channels, but on the lower flats this only occurred during spring tides. Both in and out of channels, the net asymmetry depended on the incident tide, but the asymmetry also depended on river discharge, as during high discharge periods the baroclinic pressure gradient and stratification asymmetries increased.

In the model, the sediment flux over the flats varied substantially between regions with and without distributary channels and between the southern flats and the northern flats. Net sediment fluxes were calculated through along-shore sections that roughly followed isobaths (0,1, 2, 3, and 4 m below MSL), integrating over three day periods from low-water to low-water (Fig. 14). Early in the month when discharge was greater, fluxes were strongly offshore at the river mouths, particularly on the northern flats. On the southern flats, the region of offshore flux spread laterally and weakened in the mid-flats. At the seaward edge, sediment flux was onshore, suggesting a convergence of sediment on the flats. In contrast in the north, where the flats were about half as wide, offshore fluxes extended to Whidbey Channel. An important caveat is that reduced channel stresses in the model would bias sediment fluxes landward, making the lower southern flats seem more retentive. Between the North and South Forks, flux was largely on-shore, consistent with the presence of stratification and the lack of distributary channels.

During the perigean spring tides later in the month (Fig. 14), the sediment fluxes over the flats had similar spatial structure, but were modified by the shifts in river discharge and tidal amplitude. Sediment fluxes out the river mouths weakened with the decrease in discharge, but the region off the North Fork continued 
to efficiently move sediment seaward. Between the river mouths, net flux remained on-shore. However, the flux at the seaward edge of the southern flats switched toward offshore, due to the emergence of the channels during the extremely low tides.

\section{Discussion and summary}

The critical elements that distinguish deltaic tidal flats from those without river input are freshwater buoyancy, a fluvial sediment supply, and distributary channels that carry discharge after the tide has receded. For sediment transport, the results here suggest that the distributary channels are essential conduits for moving sediment across the flats and offshore. Buoyancy from the river affects velocity and stress asymmetries on the tidal flats, and thus the sediment transport. The density gradient and periodic stratification shift velocities toward flood dominance and sediment flux landward. Asymmetries in the barotropic tide also impact the net sediment flux, particularly diurnal asymmetries in the incident tide that

modulate through the spring-neap cycle. The velocity skewness due to tidal and fluvial processes provides a good indication of sediment transport potential, but settling lag enhances landward transport, particularly for slowly settling particles and extended high-water slacks.

Comparisons between the model and observations found modest skill scores for stress and suspended sediment, and are indicative of challenges that remain in modeling shallow estuarine sediment transport. Major dynamical differences between the channels and adjacent flats were evident in both the model and observations. While the channels ( 50 to $200 \mathrm{~m}$ width, $\sim 0.2$ to $1.0 \mathrm{~m}$ depth) are subtle features on the scale of the tidal flats and are challenging to resolve in bathymetric surveys or in model grids, they were the dominant flow features at shallow water depths. The model grid spacing was about $20 \mathrm{~m}$ in channelized regions, but this resolution was inadequate for all but the largest channels. Even if a finer model grid were computationally feasible, the channels would be under-resolved in the bathymetric data. LiDAR measurements at extreme low tides can define channel locations on the exposed flats, but do not penetrate turbid water to locate the channel bottom. Acoustic measurements have limited spatial coverage 
and multi-beam swaths are extremely narrow in shallow water. Channel resolution is important not only for fluvial tidal flats, but also for drainage channels without river input, where tidal asymmetries in sediment flux have also been observed (Mariotti and Fagherazzi, 2011; Nowacki and Ogston, this issue).

Modeling intertidal regions requires numerical wetting and drying, which in FVCOM means setting a minimum water depth $\left(h_{\min }\right)$ below which no flux is permitted in or out of a cell. For these simulations $h_{\min }$ was $10 \mathrm{~cm}$, equal to or less than the minimum depth in most coastal models. For large values of $h_{\min }$, the region of elevated stress and SSC at the leading and trailing edges of the tidal water surface are poorly resolved; for small values of $h_{\min }$, the model becomes numerically unstable. Numerical experiments have found that decreasing $h_{\min }$ can affect calculated sediment transport, with about a $50 \%$ increase in landward flux due to enhanced settling lag when $h_{\min }$ decreased from $10 \mathrm{~cm}$ to $2 \mathrm{~cm}$ (Hsu et al., this issue). That study modeled an idealized tidal flat, but decreasing $h_{\min }$ may have the opposite effect on net flux for realistic bathymetries that includes channels. The flux limitation as water depths approach $h_{\min }$ reduces drainage into the channels, reducing the seaward velocities and transport in late in the ebb compared with the observations (Fig. 11), and reducing seaward sediment flux in both distributary and drainage channels.

The model results suggest that a significant fraction of the sediment supplied by the river during the freshet was trapped on the southern tidal flats, and that net export occurred only during extremely low spring tides. However, analysis of bed sediment samples from this period found only limited evidence on the flats of the geochemical tracer ${ }^{7} \mathrm{Be}$, which is typically indicative of fine-grained sediment that has recently been delivered by the river (Webster et al., this issue). Temporary deposits of fine-grained material were found near distributary channels after flow events, but at seasonal time scales most of the new mud was exported to deeper basins offshore. The discrepancy in apparent trapping on the flats has several possible explanations. Poorly resolved channels could reduce the ebb transport in the model, particularly mid-flats where the channels are smaller and intricately braided (Fig. 2). Over much of the lower flats, eel grass beds outside of the channels may provide an additional mechanism for enhancing seaward fluxes that is not in the model. Vegetation increases drag, inhibiting flow that might otherwise go 
directly to Whidbey Channel and instead focusing drainage into channels. In the model, fine sediment was exported more readily than coarse, consistent with indications from the geological observations that trapping of fine sediment is more limited than for coarser material.

Uncertainties in the sediment parameters and boundary conditions also likely affected the sediment transport results. The initial bed sediment distribution was assumed to be uniform composition, with $40 \%$ sand and the rest finer sediment. In the vicinity of channels, bed surface samples had mud fractions between 20 and 60\%, but on the tidal flats the fine fraction was much less, about 3\% (Webster et al., this issue). The model runs were not long enough for the bed composition to approach equilibrium, and the errors in bed composition may have contributed to net landward flux, by allowing resuspension of fine material and subsequent transport onshore by the residual currents.

An additional mechanism for offshore transport of fluvial sediment is wave forcing. On tidal flats without river input, sediment transport due to tidal processes is generally landward, while transport under waves is typically offshore (Le Hir et al., 2000; Yang et al., 2003). During these freshet observations, the winds were generally weak, and waves likely did not significantly alter the bottom stress or sediment transport. However, waves are more likely to be important during the late fall and winter storms that deliver more than half of the sediment load from the river (Collins, 1998). While winter storm discharge events significantly increase the supply of fine sediment to the flats, strong winds from the south that accompany the storms generate waves that would tend to keep sediment in suspension and promote export from the flats. Strong south winds would also create surface stresses that would reduce stratification on the tidal flats, and may drive more of the sediment export from the flats northward toward Deception Pass. Additional observations and modeling of fall and winter conditions would be needed to get a more complete assessment of the fate of sediment from the Skagit River.

Despite the limitations of the model, consistent conclusions can be drawn from both the observations and the model results. On fluvial tidal flats, strong horizontal density gradients at the interface between the 
river and the subtidal region result in shallow, highly stratified flow. Estuarine stratification and the baroclinic pressure gradient reinforce the onshore flux that has been observed on tidal flats without fluvial input. In contrast, the river discharge in distributary channels that emerge when the tide recedes provide conduits for offshore sediment flux. The offshore flux in channels appears to be the primary mechanism for removing sediment delivered by the river during the freshet, and because channelization only occurs when the tide has fallen near or below the level of the flats, the export is enhanced by the lower lows of spring tides.

\section{Acknowledgements}

This work was supported by the Office of Naval Research. We thank the many colleagues who generously shared data, including Britt Raubenheimer, Steve Elgar, Ken Hooper, Jon Brozena, Eric Grossman, Kristen Webster, and Jim Thomson. We also thank Geoff Cowles for assistance with the model.

\section{References}

Chen, C., Liu, H., Beardsley, R.C., 2003. An unstructured grid, finite-volume, three-dimensional, primitive equations ocean model: Application to coastal ocean and estuaries. Journal of Atmospheric and Oceanic Technology 20, 159-186.

Chen, S.-N., Geyer, W.R., Sherwood, C.R., Ralston, D.K., 2010. Sediment transport and deposition on a river-dominated tidal flat: An idealized model study. Journal of Geophysical Research 115, 16 PP., doi:201010.1029/2010JC006248.

Collins, B., 1998. Preliminary assessment of historic conditions of the Skagit River in the Fir Island area: Implications for salmonid habitat restoration. Skagit River System Cooperative, 72.

Curran, C.A., Grossman, E.E., Mastin, M.C., Huffman, R.L., 2012. Sediment load and distribution in the lower Skagit River, Washington, USA. Continental Shelf Research, submitted (this issue).

Dronkers, J., 1986. Tidal asymmetry and estuarine morphology. Netherlands Journal of Sea Research 20, 117-131, doi:10.1016/0077-7579(86)90036-0.

Dyer, K.R., Christie, M.C., Feates, N., Fennessy, M.J., Pejrup, M., van der Lee, W., 2000. An investigation into processes influencing the morphodynamics of an intertidal mudflat, the Dollard Estuary, The Netherlands: I. hydrodynamics and suspended sediment. Estuarine, Coastal and Shelf Science 50, 607-625, doi:10.1006/ecss.1999.0596.

Finlayson, D.P., 2005. Combined bathymetry and topography of the Puget Lowland, Washington State. University of Washington.

Friedrichs, C.T., 2011. Tidal flat morphodynamics: a synthesis, in: Hansom, J.D., Fleming, B.W. (Eds.), Treatise on Estuarine and Coastal Science, Volume 3: Estuarine and Coastal Geology and Geomorphology. Elsevier, p. 34. 
Friedrichs, C.T., Aubrey, D.G., 1988. Non-linear tidal distortion in shallow well-mixed estuaries: a synthesis. Estuarine, Coastal and Shelf Science 27, 521-545, doi:10.1016/0272-7714(88)90082-0.

Friedrichs, C.T., Aubrey, D.G., 1996. Uniform bottom shear stress and equilibrium hypsometry of intertidal flats, in: Pattiaratchi, C. (Ed.), Mixing in Estuaries and Coastal Seas, Coastal and Estuarine Studies. American Geophysical Union, pp. 405-429.

Friedrichs, C.T., Lynch, D.R., Aubrey, D.G., 1992. Velocity asymmetries in frictionally-dominated tidal embayments: Longitudinal and lateral variability, in: Prandle, D. (Ed.), Dynamics and Exchanges in Estuaries and the Coastal Zone. American Geophysical Union, Washington, DC, pp. 277-312.

Geyer, W., 1993. The importance of suppression of turbulence by stratification on the estuarine turbidity maximum. Estuaries and Coasts 16, 113-125, doi:10.2307/1352769.

Hsu, T.-J., Chen, S.-N. , Ogston, A.S., 2012. The landward and seaward mechanisms of fine sediment transport across intertidal flats in the shallow water region - a numerical investigation. Continental Shelf Research, submitted (this issue).

Le Hir, P., Roberts, W., Cazaillet, O., Christie, M., Bassoullet, P., Bacher, C., 2000. Characterization of intertidal flat hydrodynamics. Continental Shelf Research 20, 1433-1459, doi:10.1016/S02784343(00)00031-5.

Mariotti, G., Fagherazzi, S., 2011. Asymmetric fluxes of water and sediments in a mesotidal mudflat channel. Continental Shelf Research 31, 23-36, doi:10.1016/j.csr.2010.10.014.

Meade, R.H., 1969. Landward transport of bottom sediments in estuaries of the Atlantic Coastal Plain. Journal of Sedimentary Petrology 39, 222-234.

Mullarney, J.C., Henderson, S.M., 2011. Hydraulically controlled front trapping on a tidal flat. Journal of Geophysical Research 116, 12 PP., doi:201110.1029/2010JC006520.

Murphy, A.H., 1988. Skill scores based on the mean square error and their relationships to the correlation coefficient. Monthly Weather Review 116, 2417-2424.

Nash, D.B., 1994. Effective sediment-transporting discharge from magnitude-frequency analysis. Journal of Geology 102, 79-96.

Nidzieko, N.J., 2010. Tidal asymmetry in estuaries with mixed semidiurnal/diurnal tides. Journal of Geophysical Research 115, 13 PP., doi:201010.1029/2009JC005864.

Nidzieko, N.J. , Ralston, D.K., 2012. Tidal asymmetry and velocity skew on intertidal flats. Journal of Geophysical Research, in press.

Nowacki, D.J., Ogston, A.S., 2012. Water and sediment transport of channel-flat systems in a mesotidal mudflat: Willapa Bay, Washington. Continental Shelf Research, submitted (this issue).

Postma, H., 1961. Transport and accumulation of suspended matter in the Dutch Wadden Sea. Netherlands Journal of Sea Research 1, 148-180.

Pritchard, D., Hogg, A.J., 2003. Cross-shore sediment transport and the equilibrium morphology of mudflats under tidal currents. Journal of Geophysical Research 108, 15 PP., doi:200310.1029/2002JC001570.

Ralston, D.K., Geyer, W.R., Lerczak, J.A., Scully, M., 2010. Turbulent mixing in a strongly forced salt wedge estuary. Journal of Geophysical Research 115, 19 PP., doi:201010.1029/2009JC006061.

Ralston, D.K., Stacey, M.T., 2005. Longitudinal dispersion and lateral circulation in the intertidal zone. Journal of Geophysical Research 110, C07015, doi:10.1029/2005JC002888.

Ralston, D.K., Stacey, M.T., 2007. Tidal and meteorological forcing of sediment transport in tributary mudflat channels. Continental Shelf Research 27, 1510-1527, doi:10.1016/j.csr.2007.01.010.

Raubenheimer, B., D.K. Ralston, S. Elgar, D. Giffen and R.P. Signell, 2012. Observations and predictions of summertime winds on the Skagit tidal flats, Washington. Continental Shelf Research, submitted (this issue).

Speer, P.E., Aubrey, D.G., 1985. A study of non-linear tidal propagation in shallow inlet/estuarine systems Part II: Theory. Estuarine, Coastal and Shelf Science 21, 207-224, doi:10.1016/02727714(85)90097-6.

Straaten, L.M.J.U. van, Kuenen, P.H., 1958. Tidal action as a cause of clay accumulation. Journal of Sedimentary Research 28, 406-413, doi:10.1306/74D70826-2B21-11D7-8648000102C1865D. 
Sutherland, D.A., MacCready, P., Banas, N.S., Smedstad, L.F., 2011. A model study of the Salish Sea estuarine circulation. Journal of Physical Oceanography doi:10.1175/2011JPO4540.1.

Warner, J.C., Sherwood, C.R., Signell, R.P., Harris, C.K., Arango, H.G., 2008. Development of a threedimensional, regional, coupled wave, current, and sediment-transport model. Computers \& Geosciences 34, 1284-1306, doi:10.1016/j.cageo.2008.02.012.

Webster, K.L., Ogston, A.S., Nittrouer, C.A., 2012. Delivery, reworking and export of fine-grained sediment across the sandy Skagit River tidal flats. Continental Shelf Research, submitted (this issue).

Whitehouse, R.J.S., Bassoullet, P., Dyer, K.R., Mitchener, H.J., Roberts, W., 2000. The influence of bedforms on flow and sediment transport over intertidal mudflats. Continental Shelf Research 20, 1099-1124, doi:10.1016/S0278-4343(00)00014-5.

Yang, S.-L., Friedrichs, C., Shi, Z., Ding, P.-X., Zhu, J., Zhao, Q.-Y., 2003. Morphological response of tidal marshes, flats and channels of the Outer Yangtze River mouth to a major storm. Estuaries and Coasts 26, 1416-1425, doi:10.1007/BF02803650.

Yang, Z., Khangaonkar, T., 2009. Modeling tidal circulation and stratification in Skagit River estuary using an unstructured grid ocean model. Ocean Modelling 28, 34-49, doi:10.1016/j.ocemod.2008.07.004. 


\section{Tables}

Table 1. Sediment parameters. Input parameters for the sediment model.

\begin{tabular}{|l|l|l|l|}
\hline & fine silt & silt & fine sand \\
\hline Settling velocity $\left(w_{s}, \mathrm{~mm} \mathrm{~s}^{-1}\right)$ & 0.1 & 1.0 & 10. \\
\hline Mean diameter $(\mathrm{mm})$ & 0.014 & 0.040 & 0.140 \\
\hline Erosion rate $\left(\mathrm{kg} \mathrm{m}^{-2} \mathrm{~s}^{-1}\right)$ & $1.2 \times 10^{-5}$ & $1.2 \times 10^{-4}$ & $1.2 \times 10^{-3}$ \\
\hline Critical stress for erosion $(\mathrm{Pa})$ & 0.05 & 0.08 & 0.15 \\
\hline Porosity & 0.65 & 0.60 & 0.55 \\
\hline $\begin{array}{l}\text { Fractional composition } \\
\text { (river input and initial bed) }\end{array}$ & 0.15 & 0.45 & 0.40 \\
\hline
\end{tabular}

Table 2. Correlations and skill scores. Comparisons between observations and model results for the full time series; station locations are shown in Fig. 1. For bottom stress, skills in parentheses reflect modified model results using a local $C_{d}$ at each station based on comparison with observations.

\begin{tabular}{|l|c|c|c|c|c|c|c|c|c|c|}
\hline Station & \multicolumn{2}{|c|}{$1 \mathrm{c}$} & \multicolumn{2}{c|}{ 2c } & \multicolumn{2}{c|}{ 2f } & \multicolumn{3}{c|}{$3 \mathrm{C}$} \\
\hline & $\mathrm{R}^{2}$ & $\mathrm{SS}$ & $\mathrm{R}^{2}$ & $\mathrm{SS}$ & $\mathrm{R}^{2}$ & $\mathrm{SS}$ & $\mathrm{R}^{2}$ & $\mathrm{SS}$ & $\mathrm{R}^{2}$ & $\mathrm{SS}$ \\
\hline Water level & 0.998 & 0.997 & 0.994 & 0.994 & 0.997 & 0.997 & 0.997 & 0.997 & 0.996 & 0.995 \\
& & & & & & & & & & \\
\hline Velocity, east & 0.95 & 0.95 & 0.95 & 0.95 & 0.95 & 0.94 & 0.88 & 0.87 & 0.90 & 0.90 \\
\hline Velocity, north & 0.39 & 0.33 & 0.47 & 0.45 & 0.62 & 0.56 & 0.46 & 0.39 & 0.54 & 0.52 \\
\hline Salinity, bottom & 0.80 & 0.61 & 0.81 & 0.66 & 0.77 & 0.72 & 0.71 & 0.56 & 0.61 & 0.42 \\
\hline Salinity, surface & 0.40 & 0.12 & 0.40 & -0.01 & 0.46 & 0.16 & 0.49 & 0.24 & 0.50 & 0.36 \\
\hline Stress, bottom & 0.63 & -4.4 & 0.39 & -0.24 & 0.41 & 0.14 & 0.58 & 0.45 & 0.31 & -0.13 \\
& & $(0.55)$ & & $(0.35)$ & & $(0.29)$ & & $(0.55)$ & & $(0.25)$ \\
\hline SSC, bottom & 0.29 & -2.3 & 0.12 & 0.04 & 0.14 & -5.8 & 0.40 & 0.39 & 0.19 & -3.2 \\
\hline
\end{tabular}




\section{Figures}

Figure 1

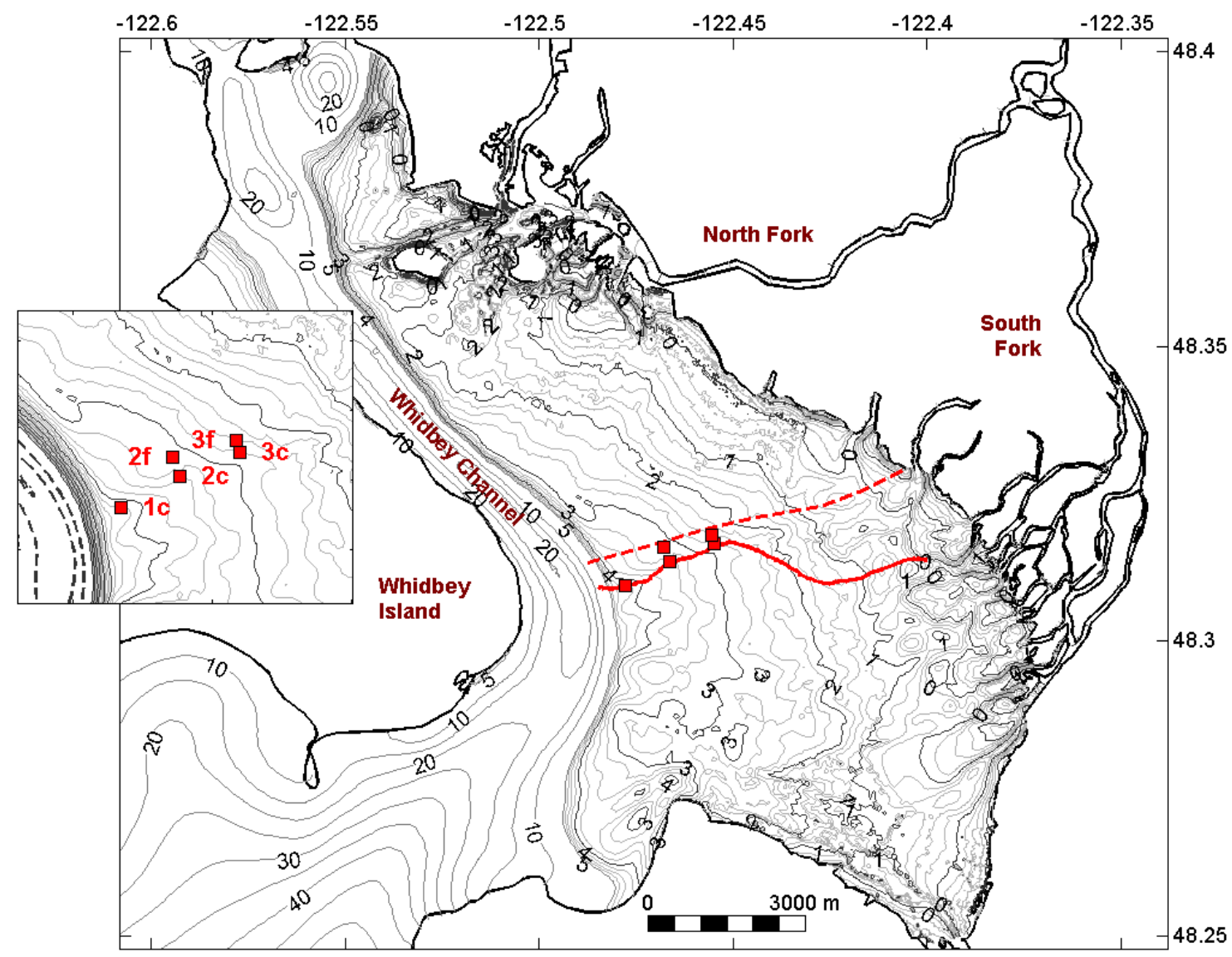

Figure 1. Map of Skagit Bay and the mouth of the Skagit River showing instrument locations (squares, labeled in inset) during field deployment. Positions of across-shore transects are shown, one following a distributary channel (solid red line) and one on adjacent flats not in a channel (dashed red line).

Bathymetric contours are relative to mean sea level. Limitations in bathymetry data resolution resulted in smoothing of distributary channel features on the tidal flat (shown in Fig. 2). 
Figure 2

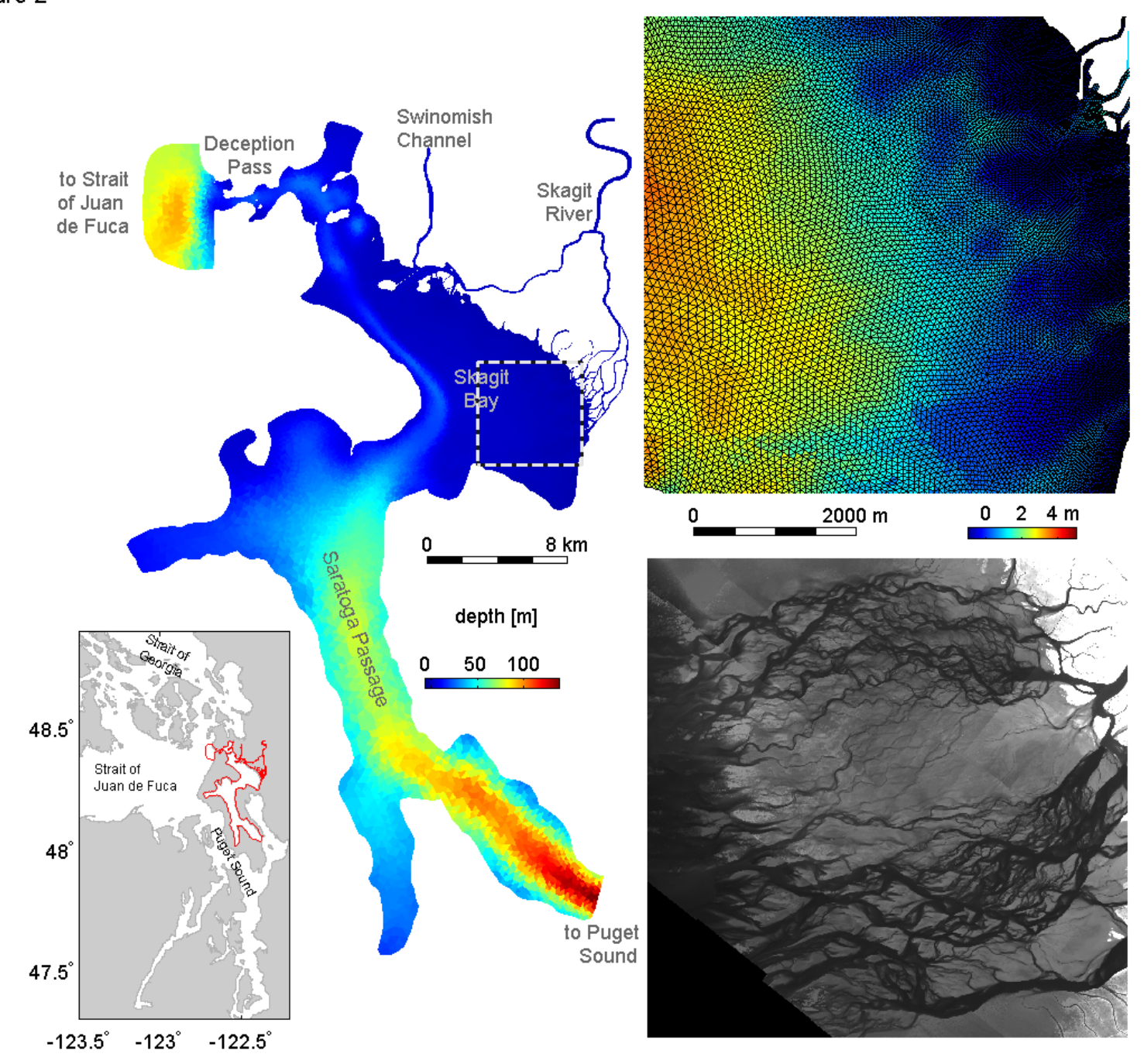

Figure 2. Model grid and detail of distributary channels. (left) Extent of model grid (location of right panel details on southern tidal flats shown in box). (upper right) Detail on southern tidal flats region showing grid resolution. (lower right) Near infrared aerial image showing distributary channel network at a low tidal stage (image courtesy K. Hooper, Arete Associates). Inset in lower left shows model grid location (outlined in red) relative to the surrounding Puget Sound and Strait of Juan de Fuca. 
Figure 3
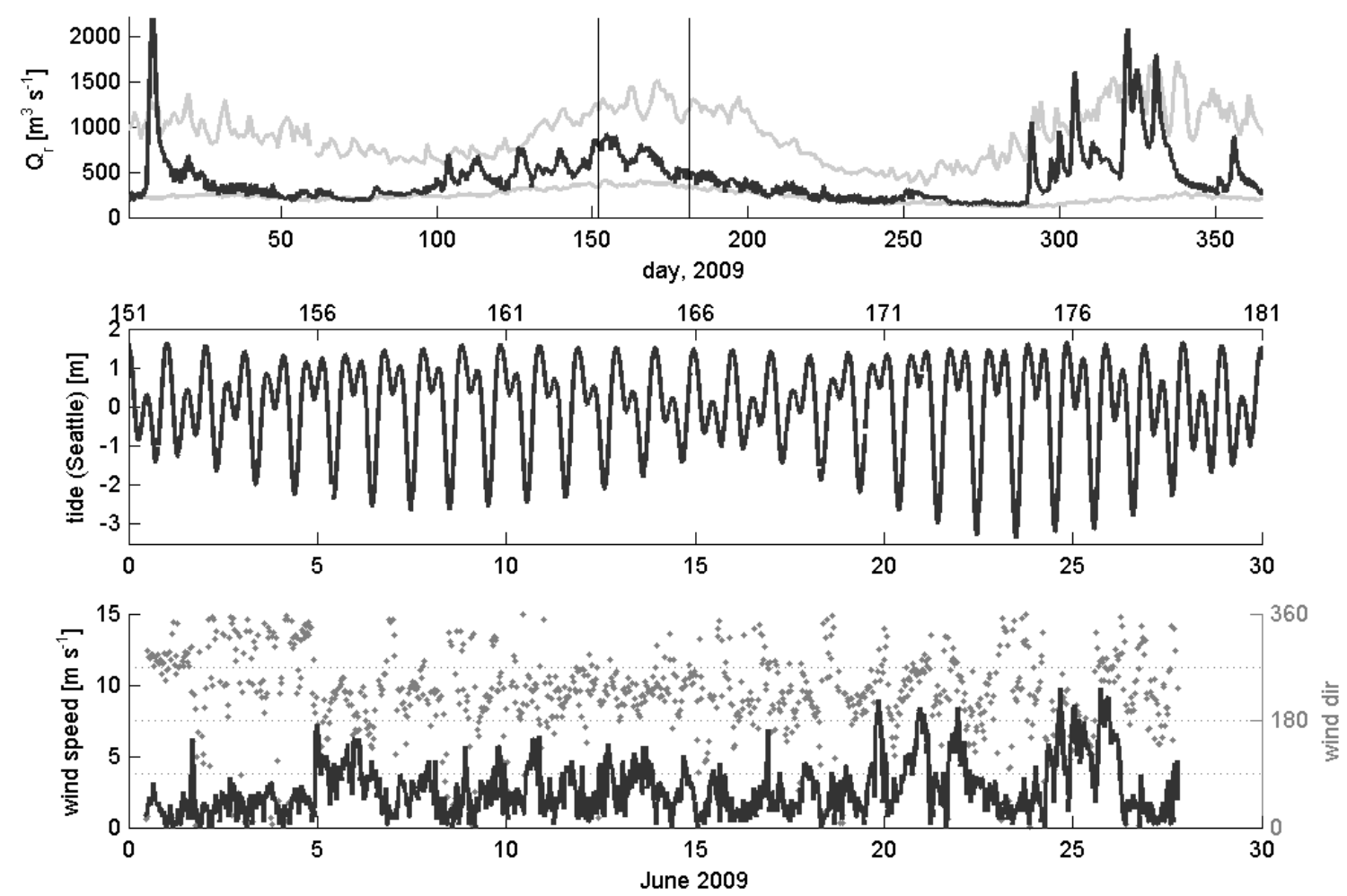

Figure 3. Forcing during observations. (top) Skagit River discharge in 2009 (black line) and the $5^{\text {th }}$ and $95^{\text {th }}$ percentile of discharge over the period 1941-2010 (gray lines, data from the USGS station \#1220050 at Mount Vernon); vertical lines denote the period of observations; (middle) tides at Seattle during the June 2009 observations (NOAA station \#9447130, relative to MSL); (bottom) wind speed and direction observed from meteorological buoy on tidal flats (at station 1c). 
Figure 4

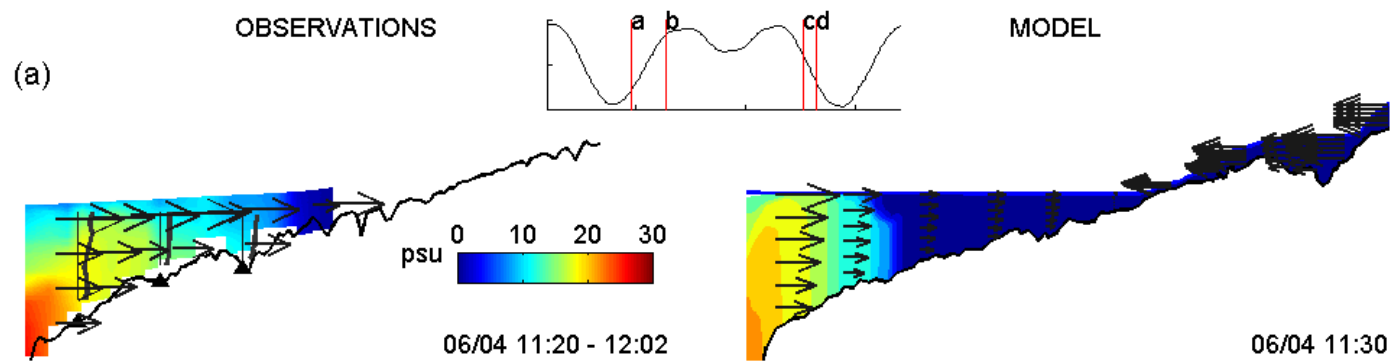

(b)
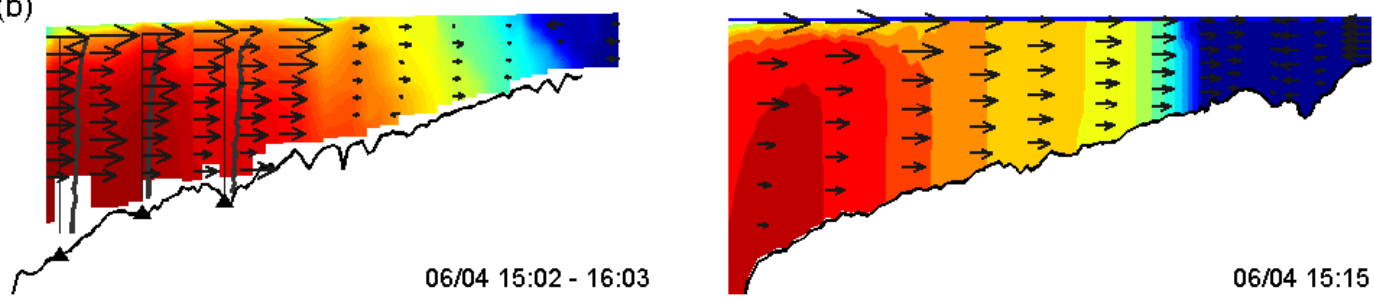

(c)

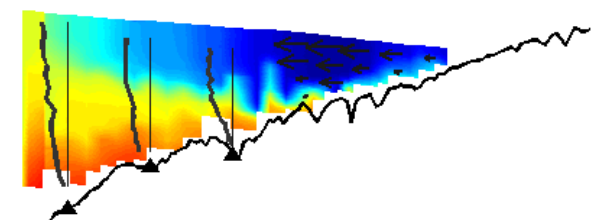

06/05 06:03- 07:06
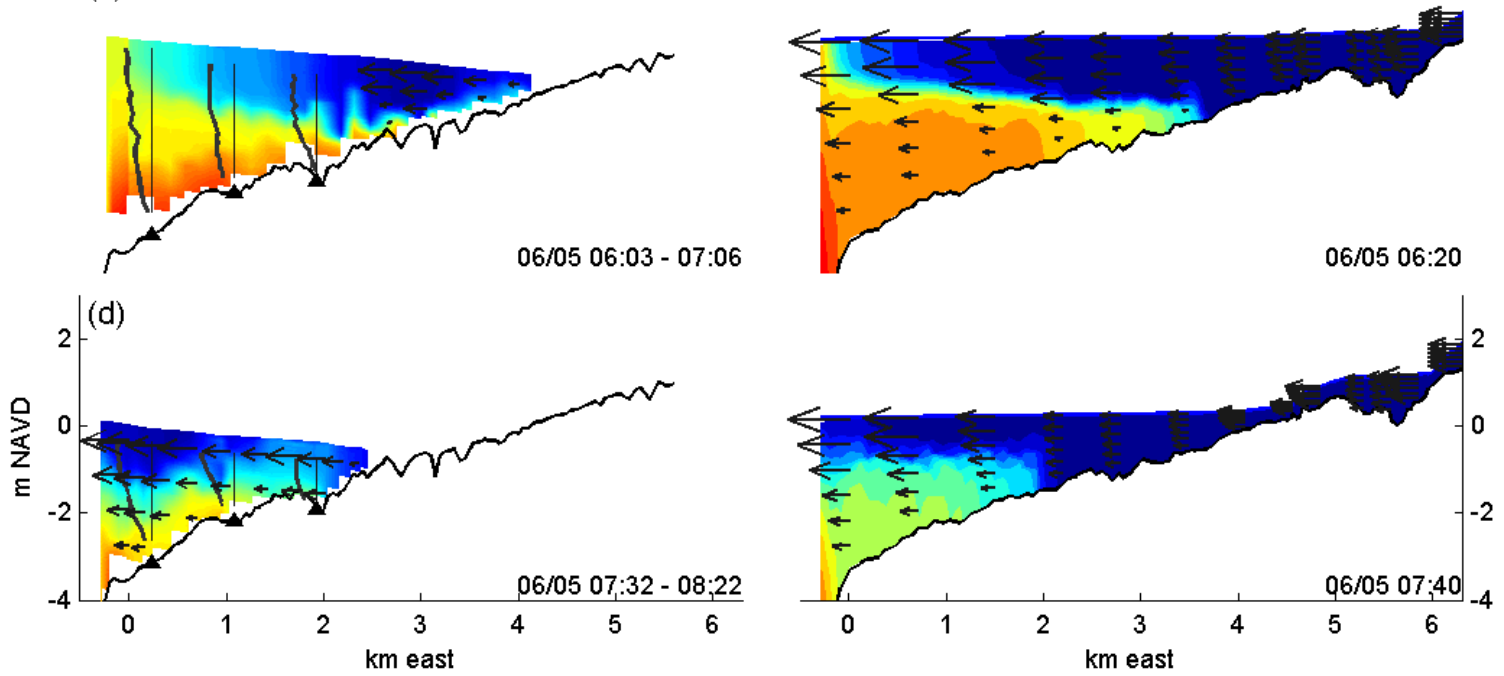

Figure 4. Across-shore salinity transects from the observations (left) and model (right). Sections were taken during a large flood (top 2 rows) and large ebb (bottom 2 rows) under high-discharge conditions $\left(\mathrm{Q}_{\mathrm{r}}\right.$ $\sim 850 \mathrm{~m}^{3} \mathrm{~s}^{-1}$ ). Tidal phasing is shown at the top. Observed velocities are from the shipboard ADCP (arrows) and moored ADCPs at stations 1c, 2c, and 3c (profile plots). Shipboard velocities were unavailable for part of the $3^{\text {rd }}$ transect due to problems with data collection. Note that the observations did not extend up the shallow channelized flows above the level of the tide due to vessel draft limitations. The 
sloping water level in the observations reflects the change in tidal elevation during the time of sampling for each transect.

Figure 5
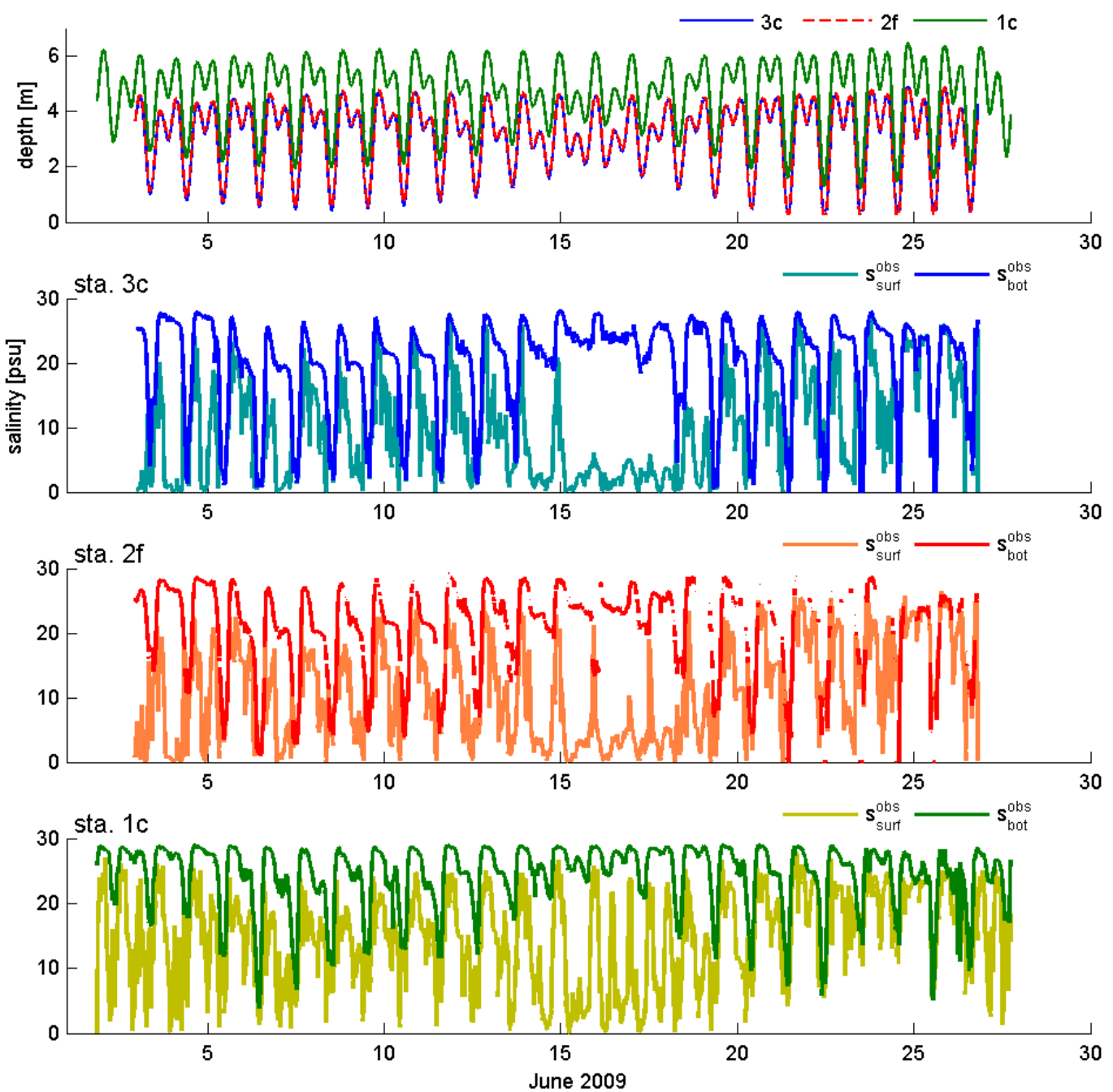

Figure 5. Water-level and salinity time series from the observations. (top) Water levels from three stations (locations shown in Fig. 1), two in a distributary channel (1c and 3c) and one on the adjacent flats (2f,at an elevation similar to 3c). (lower panels) Bottom and surface salinities at those 3 stations. A detail of the salinity time series is shown in Fig. 9. 
Figure 6
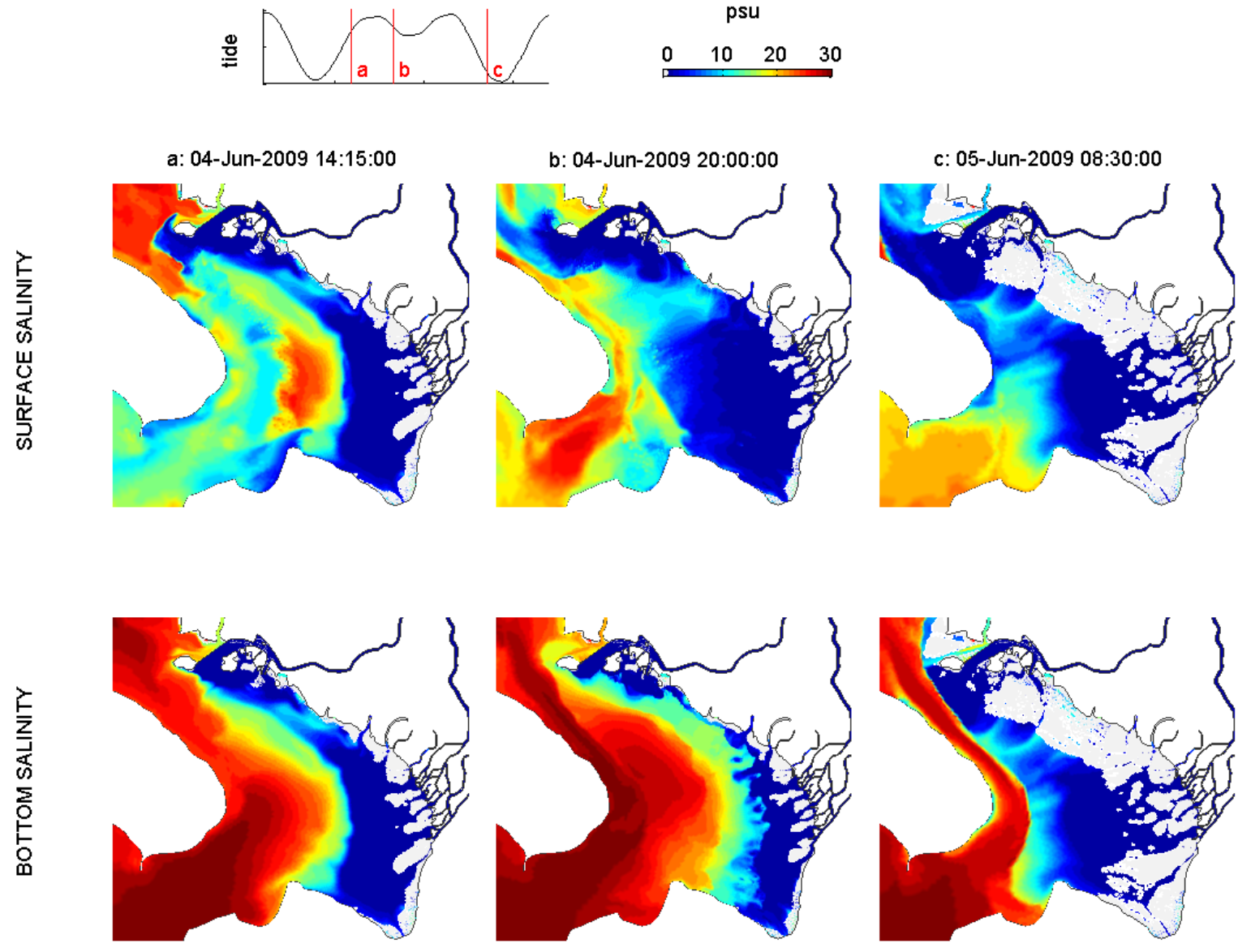

Figure 6. Model results showing maps of surface (top panels) and bottom (bottom panels) salinity in Skagit Bay at times similar to the across-shore transects shown in Fig. 4. Tidal phasing is shown in the top panel. 
Figure 7
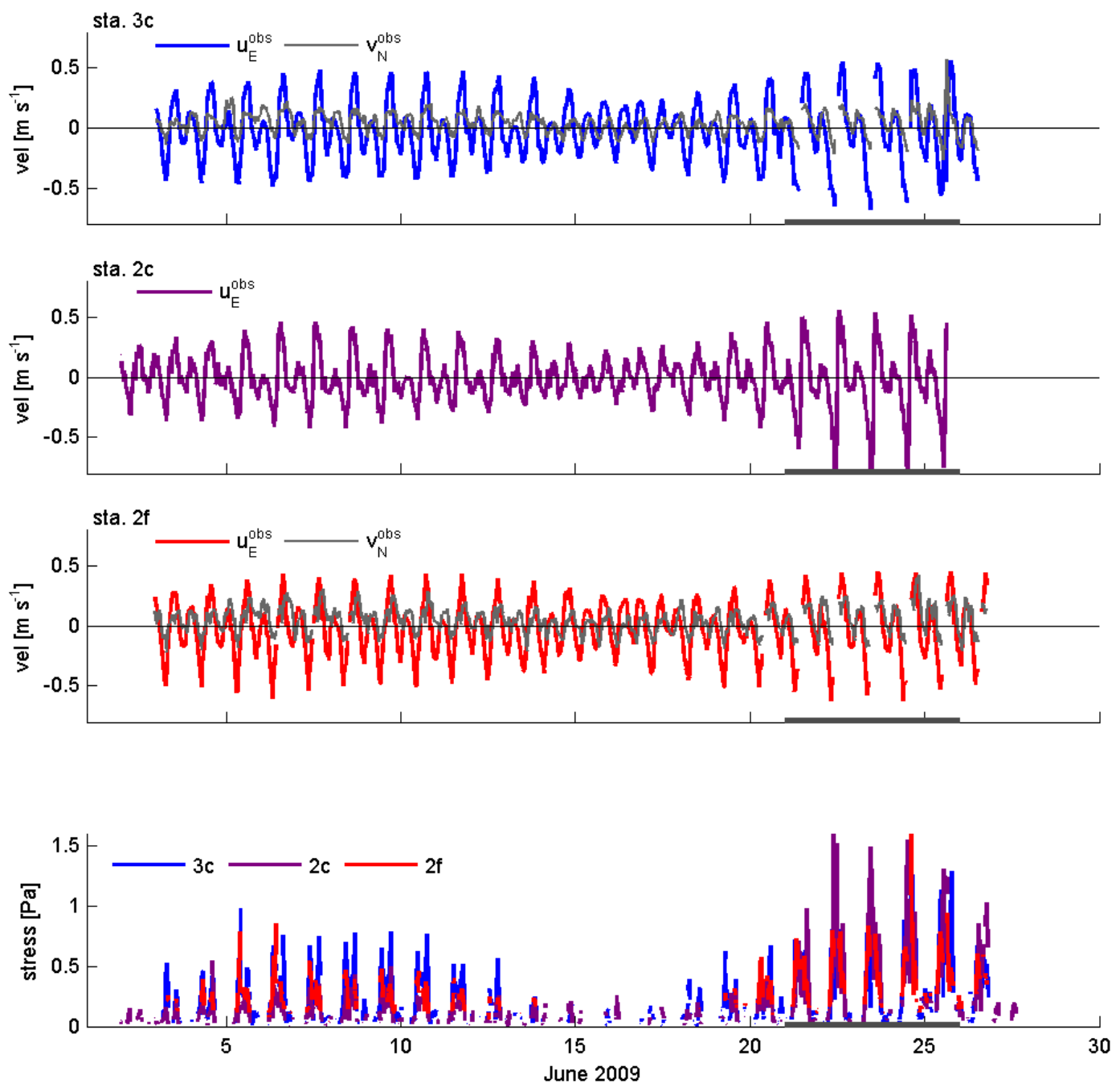

Figure 7. From the observations, time series of eastward $\left(u_{E}\right)$ and northward $\left(v_{N}\right)$ velocity and near-bed stress $\left(\tau_{b}\right)$ from stations 3c, 2c, and 2f. Velocities are depth averages from ADCPs at stations 3c and 2f, and from an ADV (40 cm above the bed) at station 2c. Bottom panel is near-bed stress at each station based on inertial dissipation fits of 10-minute ADV bursts. Gray bar indicates focus period shown in Fig. 8. 
Figure 8
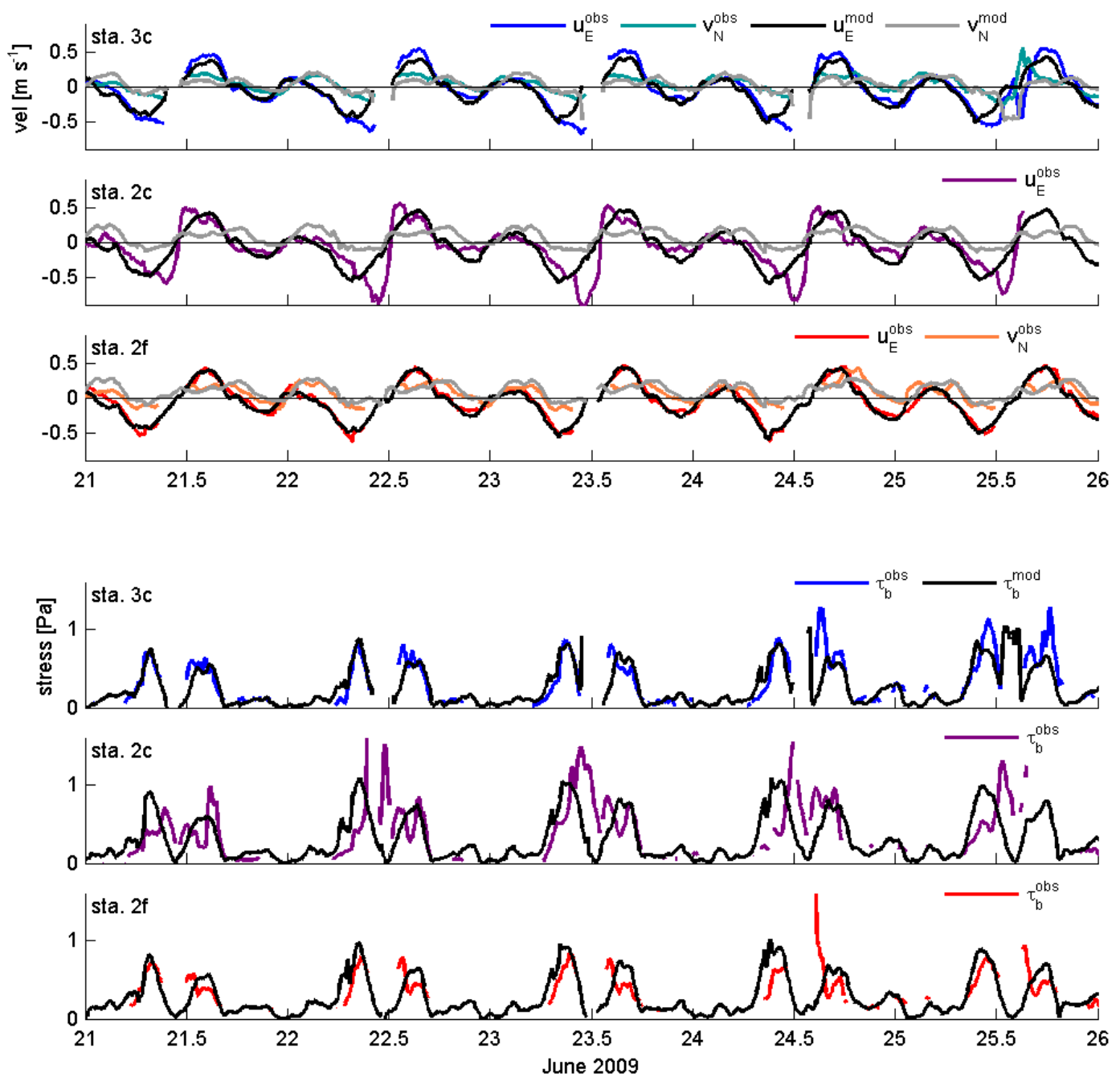

Figure 8. Near-bottom velocity (top panels) and stress (bottom panels) time series from the model and observations at stations 3c, 2c, and 2f, focusing on the perigean spring tides toward the end of the month. Observations are in color and model results are in black/gray. 
Figure 9
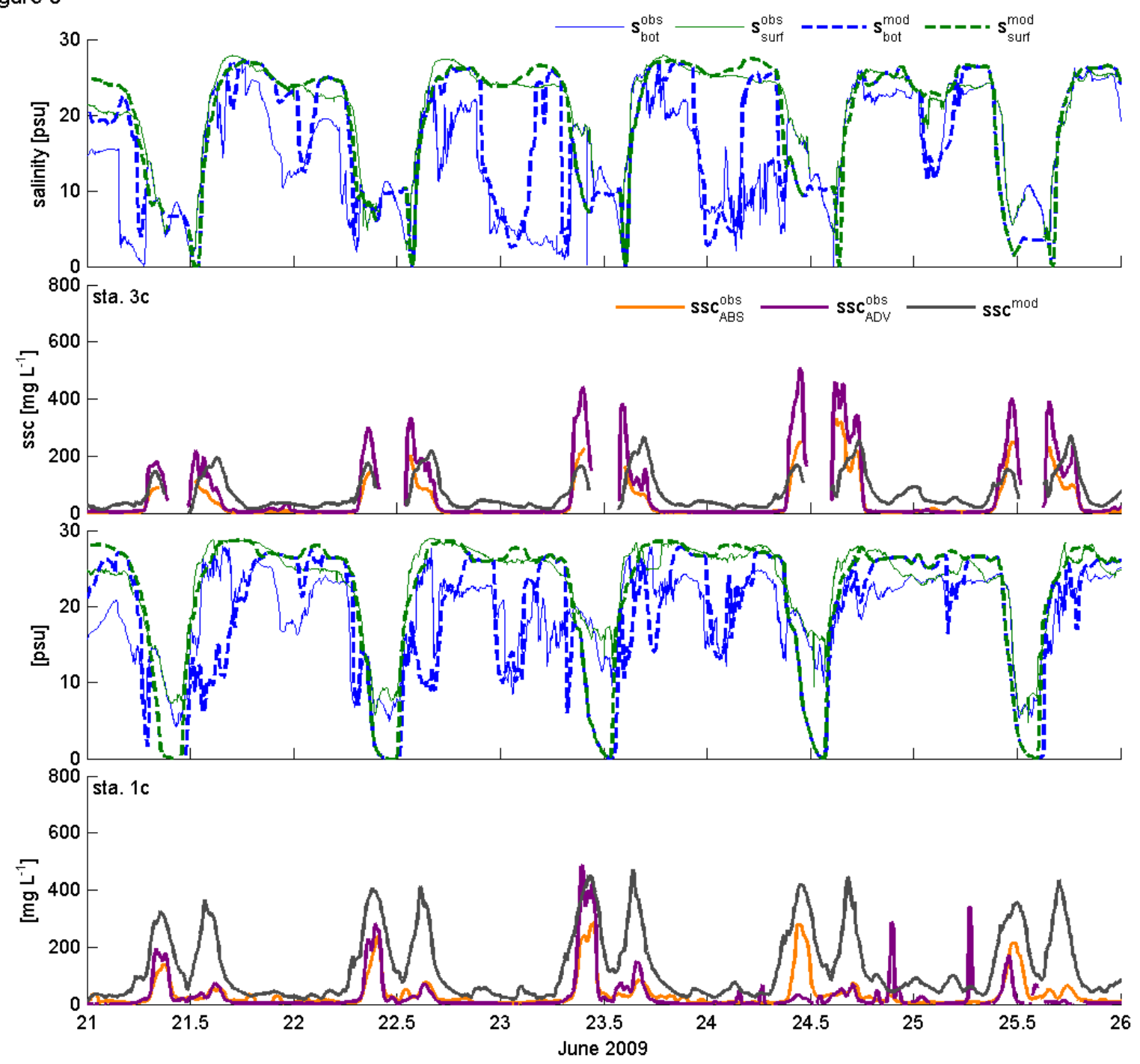

Figure 9. Salinity and suspended-sediment time series from stations 3c (top panels) and station 1c (bottom panels), focusing on the perigean spring tides toward the end of the month. At each station, the upper panel shows observed (solid) and model (dashed) salinities at the surface (blue) and near bed (green). The lower panel shows near-bottom suspended sediment measured with ADV (purple) and ABS (orange) acoustic backscatter along with concentration from the model (gray). 
Figure 10
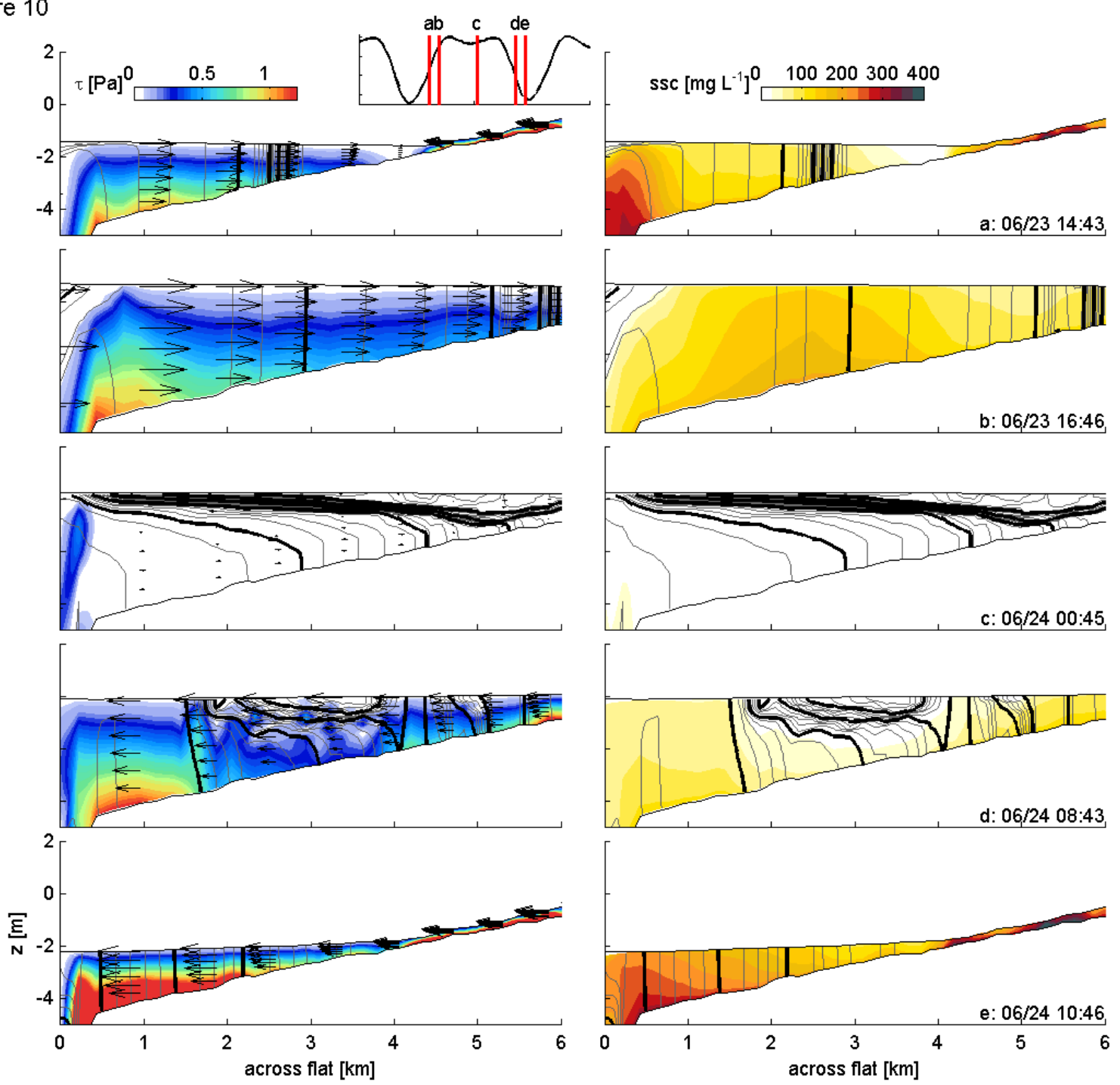

Figure 10. Across-shore transects in a distributary channel of stress (left panels) and suspended-sediment concentration (right panels) from the model results. Location of transect is same is in Fig. 4. Transects are from a diurnal period during spring tides, with snapshots during the large flood (top 2 rows), small ebb (middle row), and large ebb (bottom 2 rows). Salinity contours are shown, with intervals of 1 psu (thin gray) and 5 psu (thick black). 

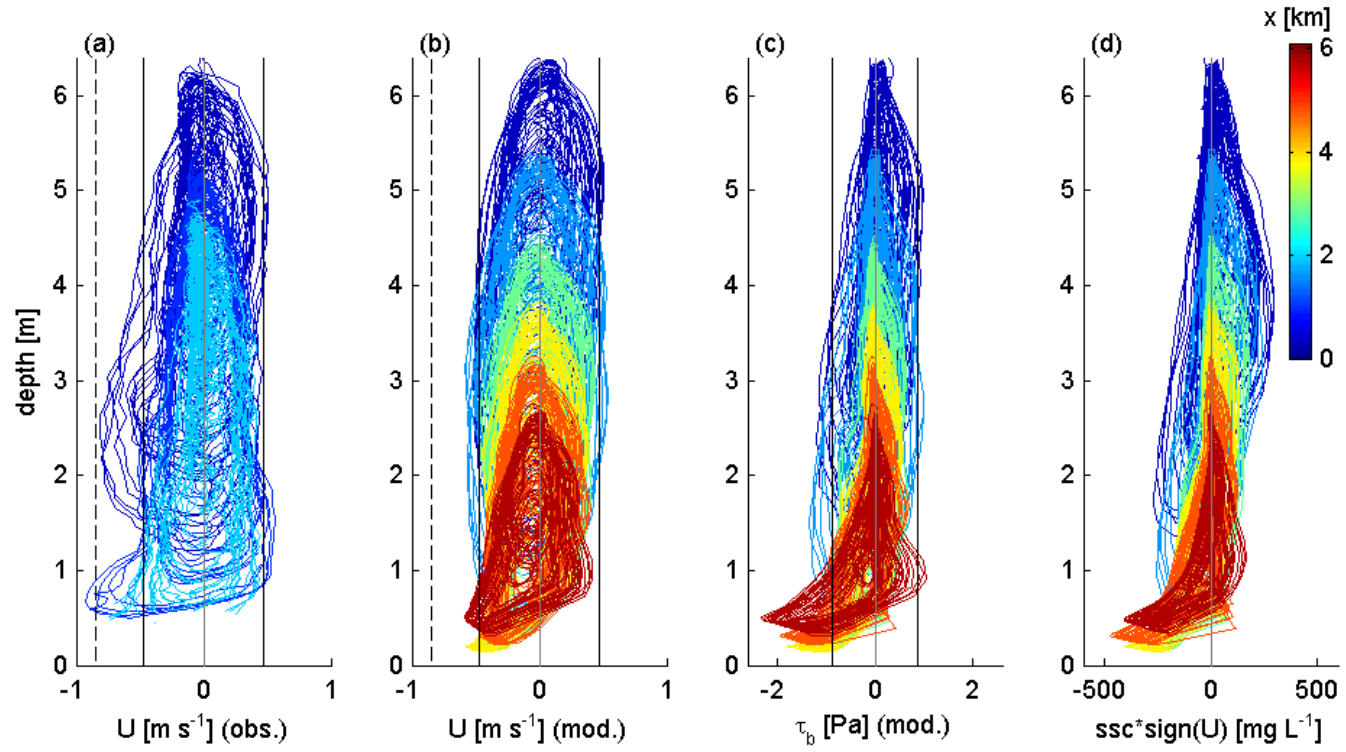

Figure 11. Velocity, bed stress, and near-bed suspended-sediment concentration versus water depth from multiple locations across the flats; colors indicate distance from the lower edge of the flats. (a) Observed velocity at stations 1c, 2c, and 3c. (b) Model velocity from locations along the channel transect (as in Figs. 4 and 10). In (a) and (b), vertical lines indicate scaling for tidal velocity (eqn. 5 with $a=2.0 \mathrm{~m}$, solid line) and for river velocity (eqn. 7 with $Q_{r}=550 \mathrm{~m}^{3} \mathrm{~s}^{-1}$, dashed line). (c) Model bottom stress from the channel transect as in (b). (d) Model near-bottom suspended-sediment concentration from the channel transect as in (b), with flow direction indicated by multiplying by the sign of the along-channel velocity. In all panels, negative values are ebb-directed. 
Figure 12
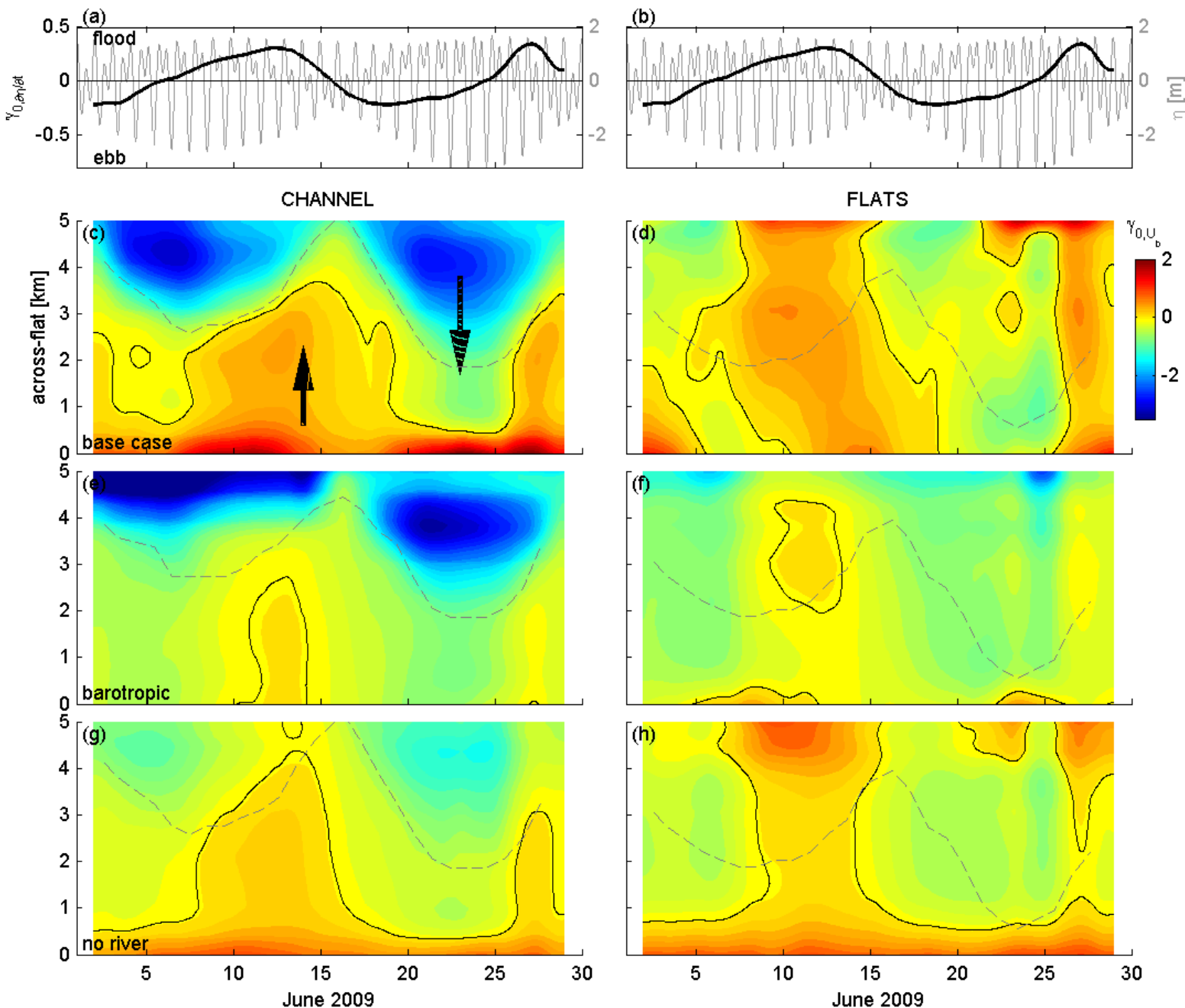

Figure 12. Modeled near-bottom velocity skewness from transects in a distributary channel (left panels) and on the adjacent flats (right panels); transect locations are shown in Fig. 1. (a/b) Tidal forcing (gray line) and associated skewness in the duration of the incident tide ( $\gamma_{0, \partial \eta / \partial t}$, black line) (panels are identical). (c/d) Near-bottom velocity skewness $\left(\gamma_{0, U b}\right)$ in the channel (c) and on the flats (d) as a function of time and distance from the lower edge of the flats; ebb-directed skewness is negative and the zero contour is noted with a black line. Gray dashed line indicates the location corresponding with the lowest tidal elevation of 
that diurnal period. (e/f) Case with barotropic physics, removing effects of density (baroclinic pressure and stratification). (g/h) Case without river discharge.

Figure 13
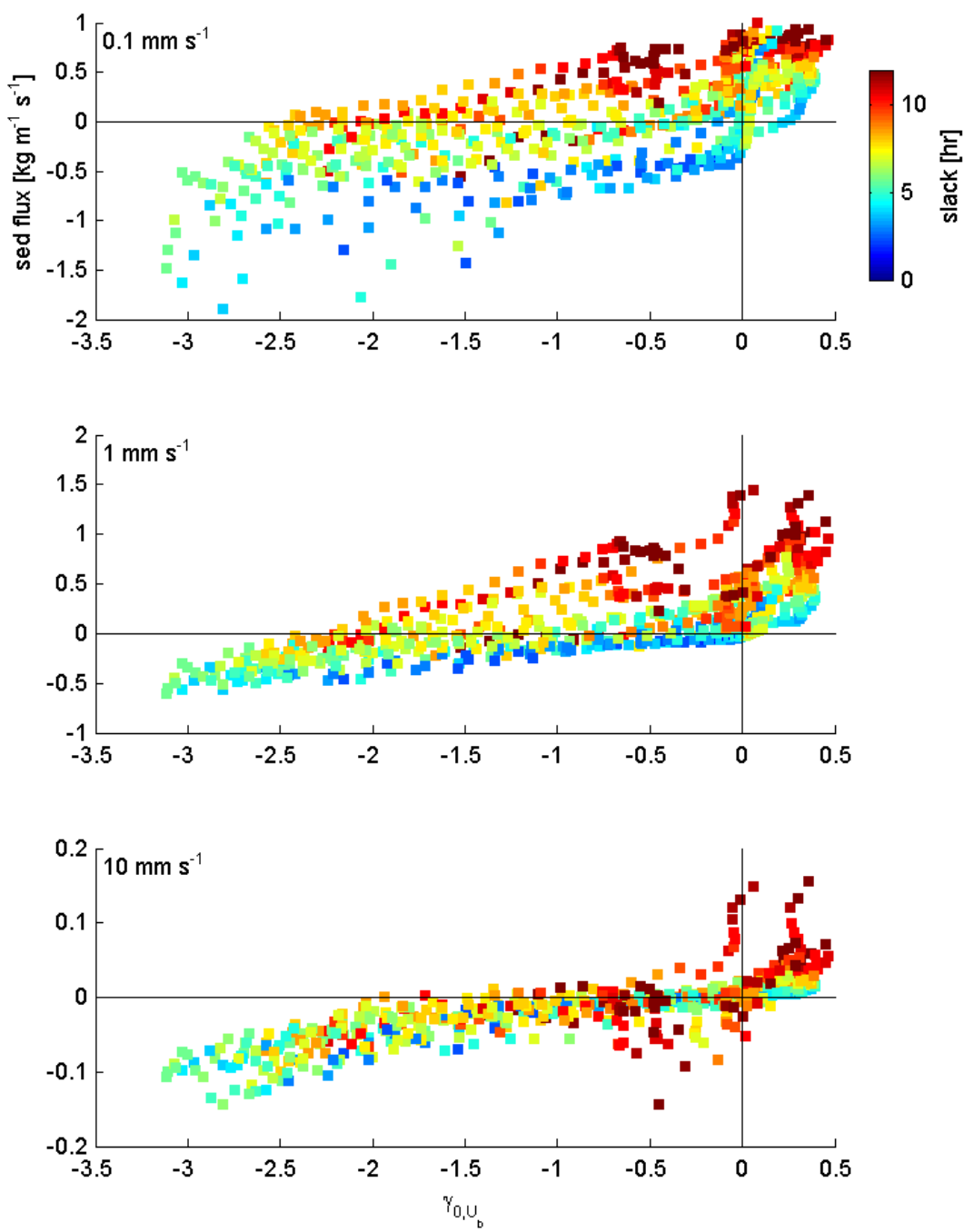

Figure 13. Modeled sediment flux and near-bottom velocity skewness $\left(\gamma_{0, U b}\right)$ from the across-shore transect up a distributary channel (as in Figs. 10-12). Sediment flux for each sediment size class ( $w_{s}=0.1$ $\mathrm{mm} \mathrm{s}^{-1}, 1 \mathrm{~mm} \mathrm{~s}^{-1}$, and $10 \mathrm{~mm} \mathrm{~s}^{-1}$ ) is integrated over diurnal periods (low water to low water) and plotted against bottom velocity skewness at that location during that tide. Marker color indicates the duration of high slack, defined here as the period around high tide when bottom stress is less than a minimum value 
(0.05 Pa). The slack duration depends both on the shape of the incident tide and the position across the tidal flat. Skewness has a tighter relationship with sediment flux for faster settling sediment; for slowly settling particles, settling lag shifts sediment flux toward flood dominance as the time of slack increases for a given bottom-velocity skewness.

Figure 14
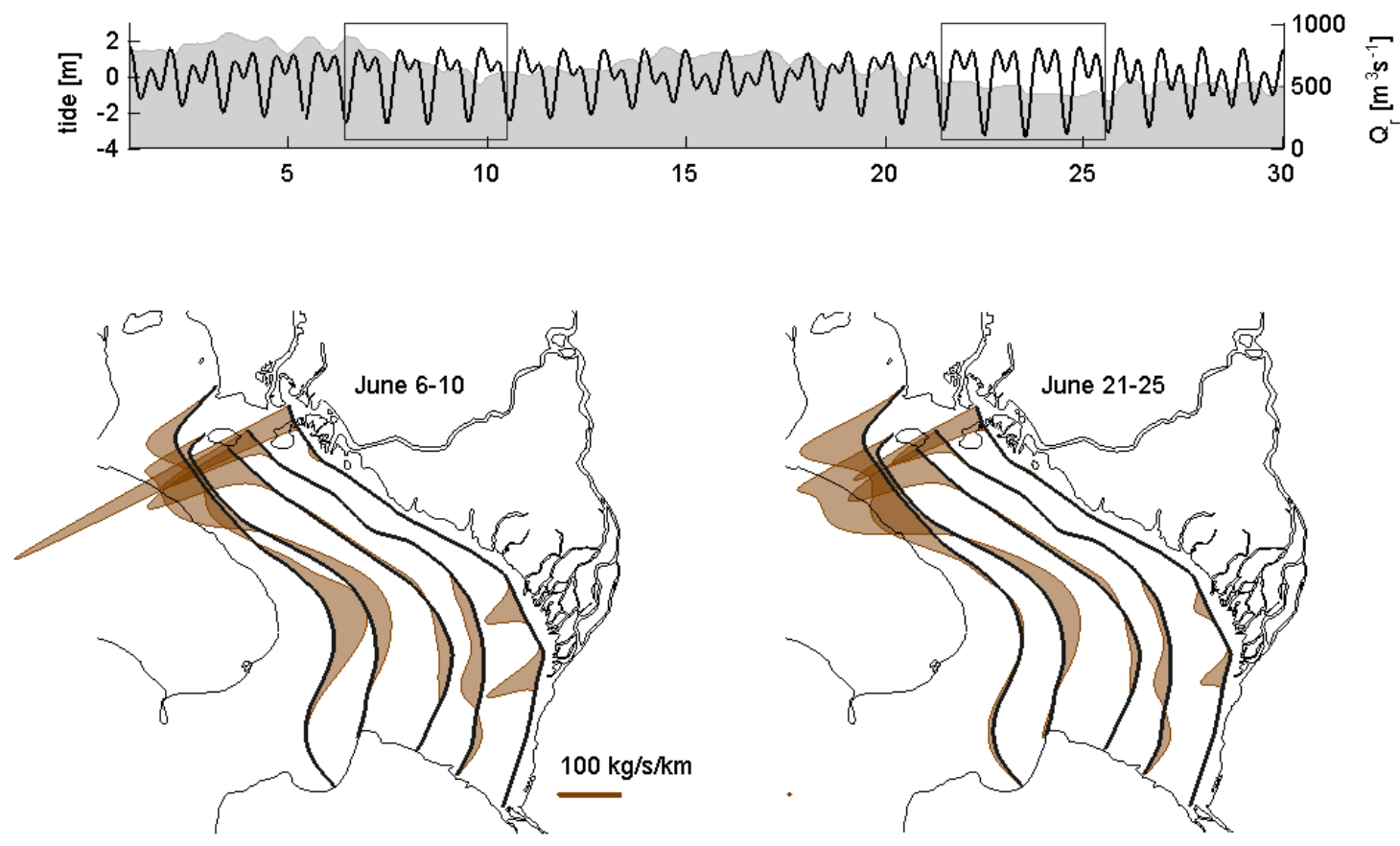

Figure 14. Sediment flux maps. Sediment flux was integrated over three tidal cycles during spring tides early in month (greater $Q_{r}$ ) and late in the month (larger tides) through sections approximately corresponding with isobaths. Top panel shows forcing (tides and river discharge), with the two averaging periods indicated by boxes. 